\title{
Evidence That Oxytocin Exerts Anxiolytic Effects via Oxytocin Receptor Expressed in Serotonergic Neurons in Mice
}

\author{
Masahide Yoshida, ${ }^{1}$ Yuki Takayanagi, ${ }^{2}$ Kiyoshi Inoue, ${ }^{3}$ Tadashi Kimura, ${ }^{4}$ Larry J. Young, ${ }^{3}$ Tatsushi Onaka, ${ }^{2}$ and \\ Katsuhiko Nishimori ${ }^{1}$ \\ ${ }^{1}$ Department of Molecular and Cell Biology, Graduate School of Agricultural Science, Tohoku University, Miyagi 981-8555, Japan, ${ }^{2}$ Department of \\ Physiology, Jichi Medical University, Tochigi 329-0498, Japan, ${ }^{3}$ Department of Psychiatry and Behavioral Sciences and Yerkes National Primate Research \\ Center, Emory University, Atlanta, Georgia 30322, and ${ }^{4}$ Department of Specific Organ Regulation, Osaka University Graduate School of Medicine, Osaka \\ 565-0871, Japan
}

The oxytocin receptor has been implicated in the regulation of reproductive physiology as well as social and emotional behaviors. The neurochemical mechanisms by which oxytocin receptor modulates social and emotional behavior remains elusive, in part because of a lack of sensitive and selective antibodies for cellular localization. To more precisely characterize oxytocin receptor-expressing neurons within the brain, we generated an oxytocin receptor-reporter mouse in which part of the oxytocin receptor gene was replaced with Venus cDNA (a variant of yellow fluorescent protein). Examination of the Venus expression revealed that, in the raphe nuclei, about one-half of tryptophan hydroxylase-immunoreactive neurons were positive for Venus, suggesting a potential role for oxytocin in the modulation of serotonin release. Oxytocin infusion facilitated serotonin release within the median raphe nucleus and reduced anxiety-related behavior. Infusion of a 5- $\mathrm{HT}_{2 \mathrm{~A} / 2 \mathrm{C}}$ receptor antagonist blocked the anxiolytic effect of oxytocin, suggesting that oxytocin receptor activation in serotonergic neurons mediates the anxiolytic effects of oxytocin. This is the first demonstration that oxytocin may regulate serotonin release and exert anxiolytic effects via direct activation of oxytocin receptor expressed in serotonergic neurons of the raphe nuclei. These results also have important implications for psychiatric disorders such as autism and depression in which both the oxytocin and serotonin systems have been implicated.

Key words: oxytocin; serotonin; anxiety-related behavior; depression; autism; dopamine

\section{Introduction}

Oxytocin (OXT) is a nonapeptide hormone that is produced primarily in the paraventricular nucleus (PVN) and supraoptic nucleus (SON) of the hypothalamus (Zimmerman et al., 1984; Gimpl and Fahrenholz, 2001). The magnocellular OXT neurons in these nuclei project to the neurohypophysis, where OXT is released into the systemic circulation. Central OXT is released from the parvocellular OXT neurons in the PVN and

\footnotetext{
Received Nov. 22, 2008; accepted Jan. 6, 2009.

This work was supported by Ministry of Education, Culture, Sports, Science, and Technology of Japan Grants 20790194 (Y.T.) and 20590237 (T.O.), and Japan Society for the Promotion of Science Grants 17005041 (M.Y.), 20020023 (T.0.), and 18380076 (K.N.). The contributions of L.J.Y. were supported by National Institute of Mental Health Grant MH64692 and National Science Foundation Grant IBN-9876754. We thank Dr. A. Smith (University of Cambridge, Cambridge, UK), Dr. Y. Katoh-Fukui (National Institute for Basic Biology, Aichi, Japan), Dr. A. Miyawaki (RIKEN, Saitama, Japan), and Dr. J. Miyazaki (Osaka University, Osaka, Japan) for their generous gifts of the ES cell line E14TG2a, the plasmid construct for Venus, and CAG-cre mice; Dr. G. Hoffman (Morgan State University, Baltimore, MD), who generously provided the JV3850 oxytocin receptor antibody; Dr. Y. Mishina (National Institute of Environmental Health Sciences, Research Triangle Park, NC) for technical advice on targeting vector construction and encouragement; and Dr. H. Yawo (Tohoku University, Miyagi, Japan) for technical help in the analysis of living brain slices.

Correspondence should be addressed to Katsuhiko Nishimori, Laboratory of Molecular Biology, Department of Molecular and Cell Biology, Tohoku University, 1-1 Tsutsumidori-Amamiyamachi, Aoba-ku, Sendai, Miyagi 9818555, Japan. E-mail: knishimo@mail.tains.tohoku.ac.jp.

DOI:10.1523/JNEUROSCI.5593-08.2009

Copyright $\odot 2009$ Society for Neuroscience $\quad 0270-6474 / 09 / 292259-13 \$ 15.00 / 0$
}

from the somatodendrites of magnocellular OXT neurons of the PVN and SON (Ludwig, 1998; Bergquist and Ludwig, 2008).

OXT acts on the oxytocin receptor (OXTR). In the brain, the OXTR is abundantly present in several brain regions (i.e., some cortical areas, the olfactory system, the basal ganglia, the limbic system, the thalamus, the hypothalamus, the brainstem, and the spinal cord) (Yoshimura et al., 1993; Vaccari et al., 1998; Gimpl and Fahrenholz, 2001), suggesting that the OXTR in the CNS has a wide variety of effects. In addition to its classical functions (i.e., induction of labor and milk ejection), OXT plays an important role in regulating social behaviors, anxiety-related behaviors, food intake, stress-related responses, and pain control (Ferguson et al., 2000; Gimpl and Fahrenholz, 2001; Takayanagi et al., 2005; Waldherr and Neumann, 2007).

We recently reported that OXTR-deficient $\left(O x t r^{-/-}\right)$mice show pervasive social deficits. Oxtr ${ }^{-1-}$ mice display defects in maternal nurturing, and Oxtr ${ }^{-1-}$ infants emit fewer ultrasonic vocalizations than wild-type littermates in response to maternal separation. Adult $O x t r^{-1-}$ males show a deficit in social discrimination and an increase in aggressive behavior (Takayanagi et al., 2005). OXT has also been shown to mediate mating-induced anxiolysis in male rat (Waldherr and Neumann, 2007). However, 
the cellular mechanisms by which the OXT-OXTR system modulates social and emotional behavior remain unknown.

In situ hybridization using radiolabeled components or ligand binding assay have demonstrated that the OXTR is distributed throughout the brain (Elands et al., 1988; Insel et al., 1993; Yoshimura et al., 1993; Vaccari et al., 1998). However, these techniques have not been useful for characterizing OXTR-expressing neurons at the cellular level. Furthermore, it has been difficult to clarify the cellular localization because of a lack of sensitive and selective antibodies for the OXTR. To precisely identify, and characterize OXTRexpressing cells in the brain, we generated a knock-in mouse strain expressing an enhanced variant of yellow fluorescent protein (Venus) under the control of the endogenous regulatory region of gene encoding the OXTR $(O x t r)$. We found that a considerable number of serotonergic neurons in the raphe nuclei express the Venus protein, and thus presumably also express OXTR. Additional experiments suggest that these receptors may mediate the anxiolytic effects of oxytocin by stimulating serotonin release.

\section{Materials and Methods}

Generation of OXTR-Venus knock-in mice and genotyping. To construct the targeting vector, mouse $129 / \mathrm{Sv}$ strain-derived genomic clones (Kubota et al., 1996) were used. The OXTRVenus knock-in vector was designed to replace part of exon 3 with Venus-poly(A) cassette with Kozak consensus sequence and bovine growth hormone poly(A) signal, and insert a phosphoglycerate kinase promoter-neomycin resistance cassette (PGK-Neo), which was surrounded by two loxP sites, into intron 3 . Venus is a variant of yellow fluorescent protein that fluoresces more efficiently than green fluorescent protein (GFP) (Nagai et al., 2002). Venus-poly(A) was inserted between ApaI and AatII sites located within exon 3; the ApaI site is positioned 62 bp downstream from the $5^{\prime}$ terminal of exon 3, and the AatII site is positioned 21 bp upstream from the $3^{\prime}$-terminal of exon 3. A $6.3 \mathrm{~kb}$ XhoI-BamHI fragment was used as the $5^{\prime}$ homology region and a $2.8 \mathrm{~kb} S p h \mathrm{I}-S p h \mathrm{I}$ fragment was used as the $3^{\prime}$ homology region. An MC1 promoter-herpes simplex virus-thymidine kinase cassette (MC1-TK) was used for negative selection. We linearized this construct with SalI and electroporated it into E14TG2a embryonic stem (ES) cells. G418 and FIAU (Moravek Biochemicals) doubly resistant clones were screened by Southern blot analysis. We generated chimeric mice by microinjection of heterozygous ES clones into C57BL/6 blastocysts. We mated chimeric males to C57BL/6J female mice. Offspring from intercrosses of heterozygous $(\mathrm{Oxtr}$ Venus-Neo/+ $)$ littermates were genotyped by Southern blot analysis. We also mated chimeric males to CAG-cre transgenic female mice (Sakai and Miyazaki, 1997) to recombine the loxP sites and yield mice with the PGK-Neo deleted allele $\left(O x t^{\text {Venus } \Delta \mathrm{Neo} /+}\right)$. The care and use of mice in this study were approved by the Institutional Animal Care and Use Committee of Tohoku University and Jichi Medical University.

Maintenance of mice. In addition to the Oxtr Venus-Neo/+ $^{\mathrm{N}}$ an Oxtr ${ }^{\text {Venus } \Delta \mathrm{Neo} /+}$ mice generated in the present study, we also used $\mathrm{Oxtr}^{-1-}$ mice generated previously (Takayanagi et al., 2005). Oxtr ${ }_{\text {Venus-Neo/+ }}$, Oxtr Venus $\Delta$ Neo/Venus $\Delta$ Neo, OxtrVenus $\Delta$ Neo/+, and

\section{SON}
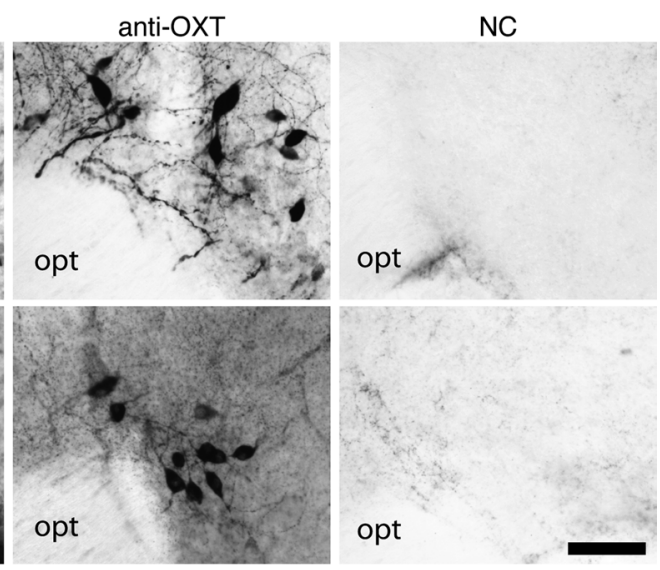

\section{PVN}

anti-OXT

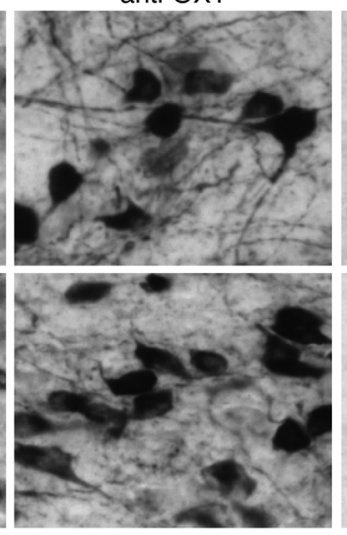

NC

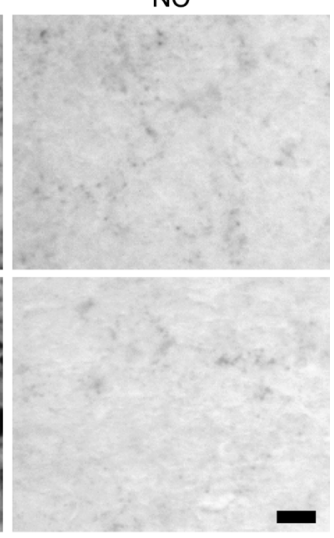

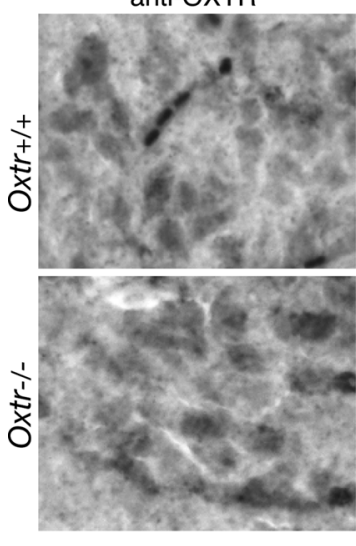

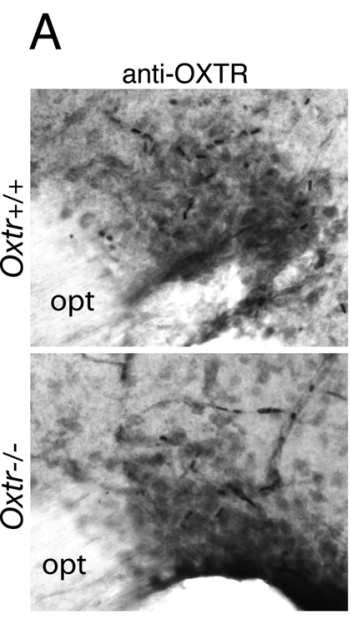

Figure 1. Immunohistochemistry using anti-OXTR and anti-OXT antibodies. In both $0 x t r^{+/+}$and $0 x t^{-1-}$, moderately immunoreactive cells for OXTR were found in SON $(\boldsymbol{A})$ and PVN $(\boldsymbol{B})$. The panels show immunoreactivity for OXTR (left), for OXT (middle), and negative control (NC) (no primary antibody) (right). Scale bars: SON, $50 \mu \mathrm{m}$; PVN, $10 \mu \mathrm{m}$. opt, Optic chiasm.

\section{$\mathrm{Oxtr}^{-/-}$mice were maintained on a mixed $129 \times \mathrm{C} 57 \mathrm{BL} / 6 \mathrm{~J}$ genetic background.}

Southern blot analysis. For Southern blot analysis, $3 \mu \mathrm{g}$ of genomic DNA extracted from the tail was digested with $\mathrm{XbaI}$ and loaded on $1 \%$ agarose gels. DNA sample was subjected to electrophoresis and transferred to Byodyne B nylon membranes (Pall). The membranes were hybridized to ${ }^{32} \mathrm{P}$-labeled probes. Probes for Southern blots were obtained by digestion with restriction enzyme, and labeled with Megaprime DNA labeling systems (GE Healthcare) with $\left[{ }^{32} \mathrm{P}\right] \mathrm{dCTP}$.

Reverse transcription-PCR analysis. Total RNA from tissues was isolated with TRIzol reagent (Invitrogen). cDNA was synthesized from DNase I-treated total RNA with Superscript II reverse transcriptase (Invitrogen) and subjected to PCR for Oxtr (GenBank accession no. D86599), Venus and acidic ribosomal phosphoprotein P0 (Arbp) (GenBank accession no. NM_007475) as control to ensure the presence of mRNA. Primers used are as follows: Oxtr, forward (5'-ACGGGTCAGTAGTGTCAAGC- $3^{\prime}$ ) and reverse (5'-TAATGCTCGTCTCTCCAGGC-3'); Venus, forward (5'-CTGACCCTGAAGCTGATCT-3') and reverse (5'-GGTAGCTCAGGTAGTGGTTG-3'); Arbp, forward (5' TGTGTGTCTGCAGATCGGGTAC- $3^{\prime}$ ) and reverse (5'-CTTTGGCGGGATTAGTCGAAG-3'). PCR products were separated on $5 \%$ polyacrylamide gels.

Receptor autoradiography. For the radioligand receptor binding, tissues were isolated, flash-frozen, sectioned at $20 \mu \mathrm{m}$, and slide-mounted. ${ }^{125}$ I-Labeled ornithine vasotosin (PerkinElmer Life and Analytical Sciences) was used for radioligand. Sections were processed for receptor autoradiography as described previously (Lim et al., 2004). 


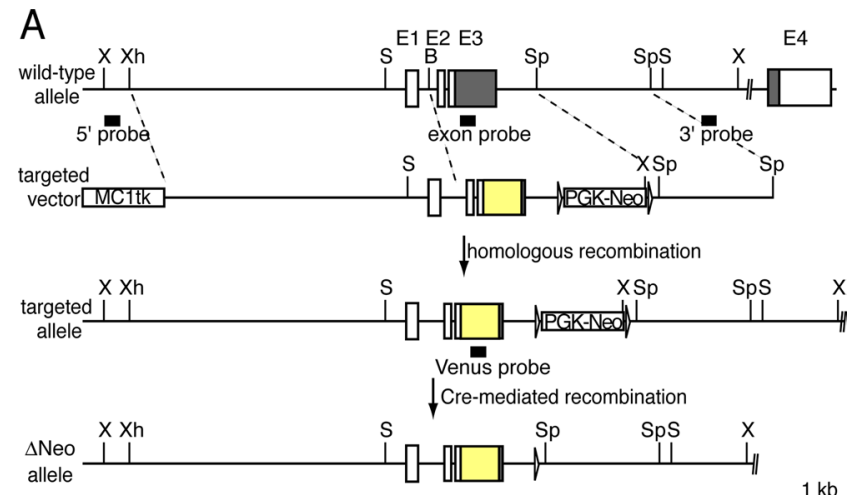

B
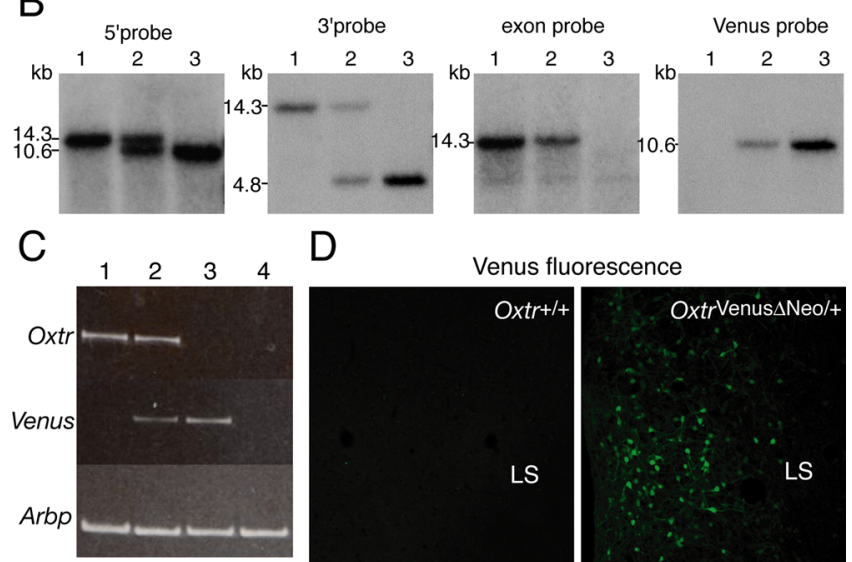

D
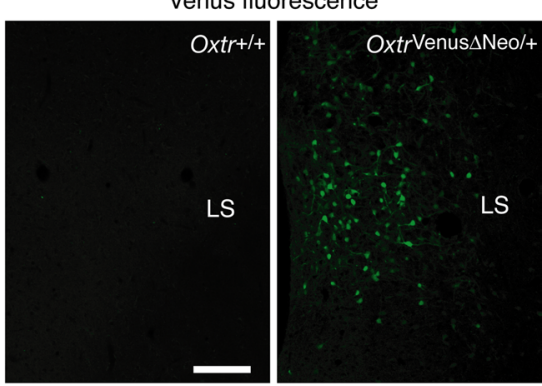

E OxtrVenus $\Delta \mathrm{NeO} /+$

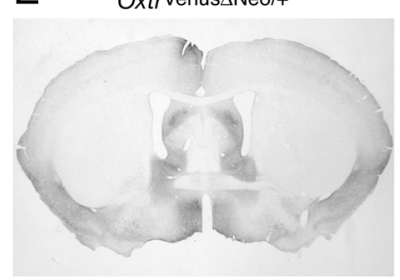

F Oxtr+1+

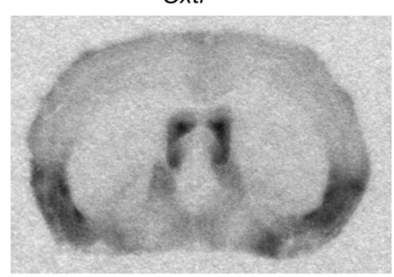

G
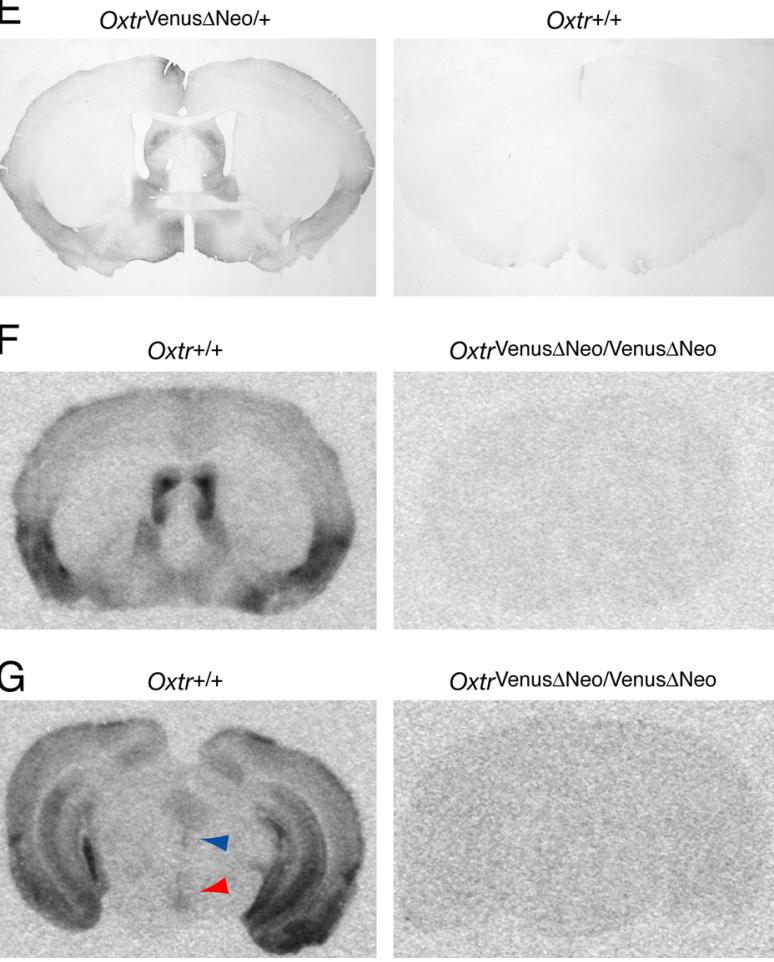

OxtrVenus $\Delta \mathrm{Neo} / \mathrm{Venus} \Delta \mathrm{NeO}$

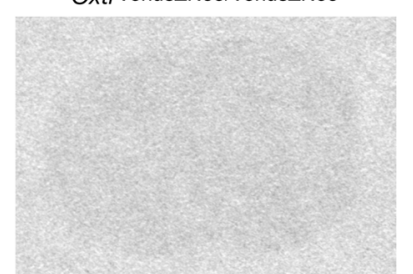

OxtrVenus $\Delta \mathrm{Neo} /$ Venus $\Delta \mathrm{NeO}$

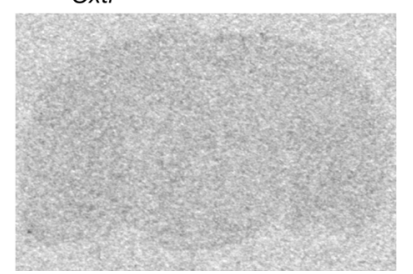

Figure 2. Generation of OXTR-Venus knock-in mice. $\boldsymbol{A}$, The wild-type and mutant $0 x$ tr loci and gene targeting constructs. Exons (E) are indicated by boxes (white boxes, $5^{\prime}$ - and $3^{\prime}$-UTRs; gray boxes, coding regions). Venus-poly $(A)$ is indicated by yellow boxes. Positions of restriction enzyme sites and the probes used for Southern blot analysis are shown (X,Xbal; Xh, Xhol; S, Sacl; $B, B a m H I ; S p, S p h l)$. The loxP sites are represented by arrowheads (not to scale). $B$, Southern blot analysis of genomic DNA from littermate progeny from intercrosses of Oxtr ${ }^{\text {Venus-Neo/+ }}$ mice.
Immunohistochemistry in $\mathrm{Oxtr}^{+/+}$and $\mathrm{Oxtr}^{-/-}$mice. Immunohistochemistry for OXT and OXTR was performed on brain tissues of adult $\mathrm{Oxtr}^{+/+}$and Oxtr ${ }^{-1-}$ mice exactly as described previously (Adan et al., 1995). Briefly, mice were transcardially perfused with paraformaldehyde-lysine-periodate fixative ( $2 \%$ paraformaldehyde, $150 \mathrm{~mm}$ lysine, 10 mu periodate), followed by overnight postfixation at $4^{\circ} \mathrm{C}$ with the same fixative. Coronal sections of $30 \mu \mathrm{m}$ thickness through the hypothalamus were incubated with rabbit anti-OXTR polyclonal antibodies, JV3850 (generously provided by Dr. G. Hoffman, Morgan State University, Baltimore, MD; diluted 1:1000) or a rabbit anti-OXT antibody (ImmunoStar; diluted 1:100) for $1 \mathrm{~h}$ at room temperature, and then for $48 \mathrm{~h}$ at $4^{\circ} \mathrm{C}$. The JV3850 anti-OXTR antibody has been shown previously to label cells within the paraventricular and/or the supraoptic nuclei of rats (Adan et al., 1995). After rinsing 10 times with $0.05 \mathrm{M}$ potassium PBS, sections were incubated with biotinylated anti-rabbit IgG (Vector Laboratories; diluted 1:600) for $1 \mathrm{~h}$ at room temperature. Sections were then rinsed eight times and placed in avidin-biotin complex solution (Vector Laboratories) for $1 \mathrm{~h}$. Immunoreactivity was visualized with the nickel chloride-3,3'-diaminobenzidine (DAB) solution (DAB substrate kit; Vector Laboratories). No immunostaining was observed in the negative control in which the primary antibody was omitted. All images were captured using a Nikon Eclipse E800 Microscope coupled with a Spot RT Slider 2.3.1 digital camera (Diagnostic Instruments).

Immunohistochemistry using commercially available anti-OXTR antibodies (H-60, N-19, C-20; Santa Cruz Biotechnology; LS-A246, LSA244; MBL) were performed on brain tissues of adult $\mathrm{Oxtr}^{+/+}$and Oxtr ${ }^{-1-}$ mice following a protocol provided by the manufacturers (data not shown).

Venus fluorescent observation and immunohistochemistry using Oxtr ${ }^{\text {Venus } \Delta \text { Neo/+ }}$ mice. The animals were deeply anesthetized with Avertin and perfused transcardially with heparinized saline $(20 \mathrm{U} / \mathrm{ml})$ followed by $4 \%$ paraformaldehyde in $0.1 \mathrm{~m}$ phosphate buffer for $10 \mathrm{~min}$. The brains were removed and postfixed in the $4 \%$ paraformaldehyde solution containing $15 \%$ sucrose overnight. They were then transferred to a $30 \%$ sucrose solution in $0.1 \mathrm{~m}$ phosphate buffer overnight. The brains were frozen on dry ice and kept in $-80^{\circ} \mathrm{C}$ until sectioning. Coronal sections $(30 \mu \mathrm{m})$ were cut using a freezing microtome and collected into $0.1 \mathrm{M}$ phosphate buffer. The sections were then processed for Venus fluorescent observation and immunohistochemical examination.

The sections were incubated overnight at $4^{\circ} \mathrm{C}$ with one of the following antibodies: anti-GFP rabbit antibody (MBL; diluted 1:1000), anti-GABA rabbit antibody (Sigma-Aldrich; 1:8000), anti-tyrosine hydroxylase (TH) rabbit antibody (Millipore Bioscience Research Reagents; diluted 1: 7500), and then incubated with Alexa 488 (for anti-GFP) or Alexa 594 (for anti-GABA and anti-TH)-labeled goat anti-rabbit antibody (Invitrogen; diluted 1:500) at room temperature. For visible detection of Venus protein, the sections were incubated overnight at $4^{\circ} \mathrm{C}$ with antiGFP, and then incubated a HISTFINE simple stain mouse MAX-PO (Nichirei) at room temperature. Venus immunoreactivity was visualized as a brown precipitate by using DAB procedure.

For double immunocytochemical detection of Venus and tryptophan hydroxylase $(\operatorname{TrH})$, sections were incubated with a sheep antibody against $\operatorname{TrH}$ (Millipore Bioscience Research Reagents; diluted 1:3500) for

\section{$\leftarrow$}

Xbal-digested tail DNA was hybridized with the radiolabeled probes indicated in Figure $1 \mathrm{~A} .5^{\prime}$ and $3^{\prime}$ probes external to the targeting vector and two internal probes were used to distinguish the wild-type ( $14.3 \mathrm{~kb}$ ) and targeted alleles ( $10.6 \mathrm{~kb}$ for the $5^{\prime}$ and Venus probes, and $4.8 \mathrm{~kb}$ for the $3^{\prime}$ probe). Lane 1, Oxtr $^{+/+}$; lane 2, Oxtr ${ }^{\text {Venus-Neo/+ }}$; lane 3, Oxtr ${ }^{\text {Venus-Neo/Venus-Neo }}$. C, Oxtr and Venus mRNA expression in the mouse brain by reverse transcription (RT)-PCR. Total RNA extracted from the brains was subjected to RT-PCR. Lane $1,0 x$ tr $^{+/+}$; lane 2, Oxtr ${ }^{\text {Venus } \Delta \text { Neo/+ }}$; lane 3, Oxtr Venus $\Delta$ Neo/Venus $\Delta$ Neo; lane 4, $0 x$ tr $^{-I-}$. D, Observation of Venus fluorescent in the $\mathrm{LS}$ of Oxtr ${ }^{\mathrm{Venus}} \Delta \mathrm{Neo} /+$ mouse. $E$, Immunocytochemical detection of Venus protein using a DAB procedure in $0 x$ tr $^{\text {Venus } \Delta \mathrm{Neo} /+}$ and $\mathrm{Oxtr}{ }^{+/+}$mice. Venus immunoreactivity was observed as a brown precipitate. $F, G, 0 X T R$-binding autoradiograms in the brain of $0 x^{+/+}{ }^{+/}$(left) and Oxtr ${ }^{\text {Venus } \Delta \text { Neo/Venus } \Delta \text { Neo }}$ mice (right). OXTR binding was observed in the $L S(\boldsymbol{F})$ and in the DR and $\operatorname{MnR}(\boldsymbol{G})$ of $0 \mathrm{xtr}^{+/+}$mice, but not $0 \mathrm{xtr}^{\text {Venus } \Delta \text { Neo/Venus } \Delta \text { Neo }}$ mice. In $\boldsymbol{G}$, blue and red arrowheads indicate the DR and MnR, respectively. Scale bar, $100 \mu \mathrm{m}$. 
Table 1. Distribution of cell bodies expressing Venus immunoreactivity in the male $0 x \mathrm{Xr}^{\mathrm{Venus} \Delta \mathrm{Neo} /+}$ mice brain

\begin{tabular}{|c|c|c|c|}
\hline Area & Cell body density & Area & Cell body density \\
\hline Cerebral cortex & & Interbrain & \\
\hline Granular cell layer of the olfactory bulb (Gr0) & ++++ & Medial preoptic area (MPA) & ++ \\
\hline Glomerular layer of the olfactory bulb (GI) & ++ & Median eminence (ME) & +-++ \\
\hline Granule cell layer of the accessory olfactory bulb (GrA) & +++ & Organum vasculosum of the lamina terminalis (OVLT) & ++++ \\
\hline Anterior olfactory nucleus ( $\mathrm{A} 0$ ) & +++ & Lateral preoptic area (LPO) & + \\
\hline Dorsal endopiriform nucleus (DEn) & +++ & Subfornical organ (SF0) & ++ \\
\hline Olfactory tubercle (Tu) & + & Xiphoid thalamic nucleus (Xi) & ++ \\
\hline Orbital/insular/prelimbic cortex & ++ & Medial tuberal nucleus (Mtu) & + \\
\hline Frontal association cortex (FrA) & + & Ventral lateral geniculate nucleus (VLG) & +-++ \\
\hline Cingulate cortex $(\mathrm{Cg})$ & ++ & Paraventricular thalamic nucleus (PV) & +-++ \\
\hline Motor cortex & + & Lateral hypothalamic area (LH) & ++ \\
\hline Dorsal peduncular cortex (DP) & + & Suprachiasmatic nucleus (SCh) & +++-++++ \\
\hline Primary somatosensory cortex (S1) & ++ & Anterior hypothalamic area (AH) & + \\
\hline Retrosplenial granular cortex (RSG) & ++ & Lateroanterior hypothalamic nucleus (LA) & +++-++++ \\
\hline Parietal association cortex (PtA) & ++ & Zona incerta (Zl) & ++ \\
\hline Secondary auditory cortex (Au) & ++ & Ventromedial hypothalamic nucleus (VMH) & ++-++++ \\
\hline Temporal association cortex (TeA) & ++ & Arcuate hypothalamic nucleus (Arc) & ++++ \\
\hline Ectorhinal cortex (Ect) & ++ & Dorsomedial hypothalamic nucleus (DM) & + \\
\hline Perirhinal cortex (PRh) & ++ & Posterior hypothalamic area (PH) & ++ \\
\hline Retrosplenial agranular cortex (RSA) & ++ & Mammillary peduncle (mp) & ++ \\
\hline Secondary visual cortex (V2) & ++ & Supramammillary nucleus (SuM) & ++ \\
\hline Piriform cortex (Pir) & ++ & Midbrain-hindbrain & \\
\hline Tenia tecta (TT) & ++ & Dorsal raphe nucleus (DR) & \\
\hline Basomedial amygdaloid nucleus (BM) & ++-+++ & Median raphe nucleus (MnR) & ++-+++ \\
\hline Cortical amygdaloid nucleus (COA) & ++++ & Pontine reticular nucleus (Pn) & ++-+++ \\
\hline Cortex-amygdala transition zone (CXA) & + & Nucleus of the solitary tract (NTS) & + \\
\hline Amygdalopiriform transition area (Apir) & + & Gigantocellular reticular nucleus (Gi) & + \\
\hline Amygdalohippocampal area (AHi) & ++-+++ & Medial vestibular nucleus (MVe) & + \\
\hline CA1 & + & Prepositus nucleus (Pr) & + \\
\hline CA2 & +-++ & Raphe pallidus nucleus (RPa) & ++++ \\
\hline CA3 & +-++ & Peripeduncular nucleus (PP) & +-++ \\
\hline Polymorphic layer of the dentate gyrus (PoDG) & +-++ & Posterior prelectal nucleus (PPT) & ++ \\
\hline Subiculum $(S)$ & +-++ & Olivary pretectal nucleus (OPT) & + \\
\hline Basal ganglia & & Periaqueductal gray (PAG) & +++ \\
\hline Olfactory tubercle (Tu) & + & Area dorsal to substantia nigra & ++-+++ \\
\hline Ventral pallidum (VP) & + & Laterodorsal tegmental nucleus (LDTg) & +-++ \\
\hline Globus pallidus (GP) & + & Subceruleus nucleus (SubC) & ++ \\
\hline Accumbens nucleus core (Acbc) & + & Parvicellular reticular nucleus (PCRt) & + \\
\hline Lateral septal nucleus (LS) & +++-++++ & Kolliker-Fuse nucleus (KF) & + \\
\hline Medial septal nucleus (MS) & +++ & Lateral parabrachial nucleus (LPB) & +-++ \\
\hline Bed nucleus of the stria terminalis (BST) & +-+++ & Intermediate reticular nucleus (IRt) & + \\
\hline Nucleus of the horizontal limb of the diagonal band (HDB) & ++++ & Nucleus $0(0)$ & +++ \\
\hline Magnocellular preoptic nucleus (MCPO) & ++++ & Barrington's nucleus (Bar) & + \\
\hline Septofimbrial nucleus (SFi) & + & Area postrema (AP) & ++ \\
\hline Anterior amygdaloid area (AA) & + & Periolivary nucleus (P0) & +++ \\
\hline Medial amygdaloid nucleus (MeA) & ++ & Cerebellum & ++ \\
\hline Central amygdaloid nucleus (CeA) & ++-+++ & Molecular layer of the cerebellar cortex (CCmol) & ++ \\
\hline Substantia innominata (SI) & + & & \\
\hline
\end{tabular}

Venus was detected by immunohistochemistry and graded as low $(+)$, intermediate $(++)$, high $(+++)$, or very high $(++++)$.

$1 \mathrm{~d}$ at $4^{\circ} \mathrm{C}$, and then incubated with Alexa 594-labeled goat anti-rabbit antibody (diluted 1:500) at room temperature. Next, these sections were labeled with anti-GFP.

For double immunocytochemical detection of Venus and glial glutamate transporter (GLAST), sections were incubated with a guinea pig antibody against GLAST (Millipore Bioscience Research Reagents; diluted 1:2000) for $1 \mathrm{~d}$ at $4^{\circ} \mathrm{C}$ and then incubated with Alexa 594-labeled goat anti-guinea pig antibody (diluted 1:500) at room temperature. Then, these sections were labeled with anti-GFP.

To investigate colocalization between GABA and Venus, or between $\mathrm{TH}$ and Venus, we examined GABA immunoreactivity plus Venus fluorescence or TH immunoreactivity plus Venus fluorescence. We compared Venus fluorescence and Venus immunoreactivity observed with Alexa 594 in sections of lateral septal nucleus (LS), dorsal raphe nucleus (DR), median raphe nucleus (MnR), and nucleus of the solitary tract
(NTS), and found that $>90 \%$ Venus-immunoreactive cells showed detectable Venus fluorescence (data not shown).

Fluorescence was observed with a laser-scanning confocal microscope FV1000 (Olympus). A three-dimensional image was constructed from serial tomograms following a protocol provided by the manufacturer.

Microdialysis. In the experiments with microdialysis, C57BL/6J (SLC) male mice were anesthetized with urethane (ethyl carbamate, $2.1 \mathrm{~g} / \mathrm{kg}$ body weight, intraperitoneal injection), tracheotomized, and placed in a stereotaxic frame. A microdialysis probe $(0.24 \mathrm{~mm}$ outer diameter, $1 \mathrm{~mm}$ length membrane; concentric design probe; CUP11; CMA/Microdialysis) was lowered into the $\mathrm{MnR}$ (coordinates, $4.72 \mathrm{~mm}$ caudal to the bregma; on the midline; $4.26 \mathrm{~mm}$ below the skull) after retracting the central sinus. Artificial CSF ( $138 \mathrm{~mm} \mathrm{NaCl}, 5 \mathrm{~mm} \mathrm{KCl}, 1.5 \mathrm{~mm} \mathrm{CaCl}_{2}, 1$ $\mathrm{mm} \mathrm{MgCl}_{2}, 11 \mathrm{~mm} \mathrm{NaHCO}, 1 \mathrm{~mm} \mathrm{NaPO}_{4}, \mathrm{pH} 7.2$ ) was passed through the probe at $1.33 \mu \mathrm{l}$ per min using a syringe pump, and $15 \mathrm{~min}$ samples 

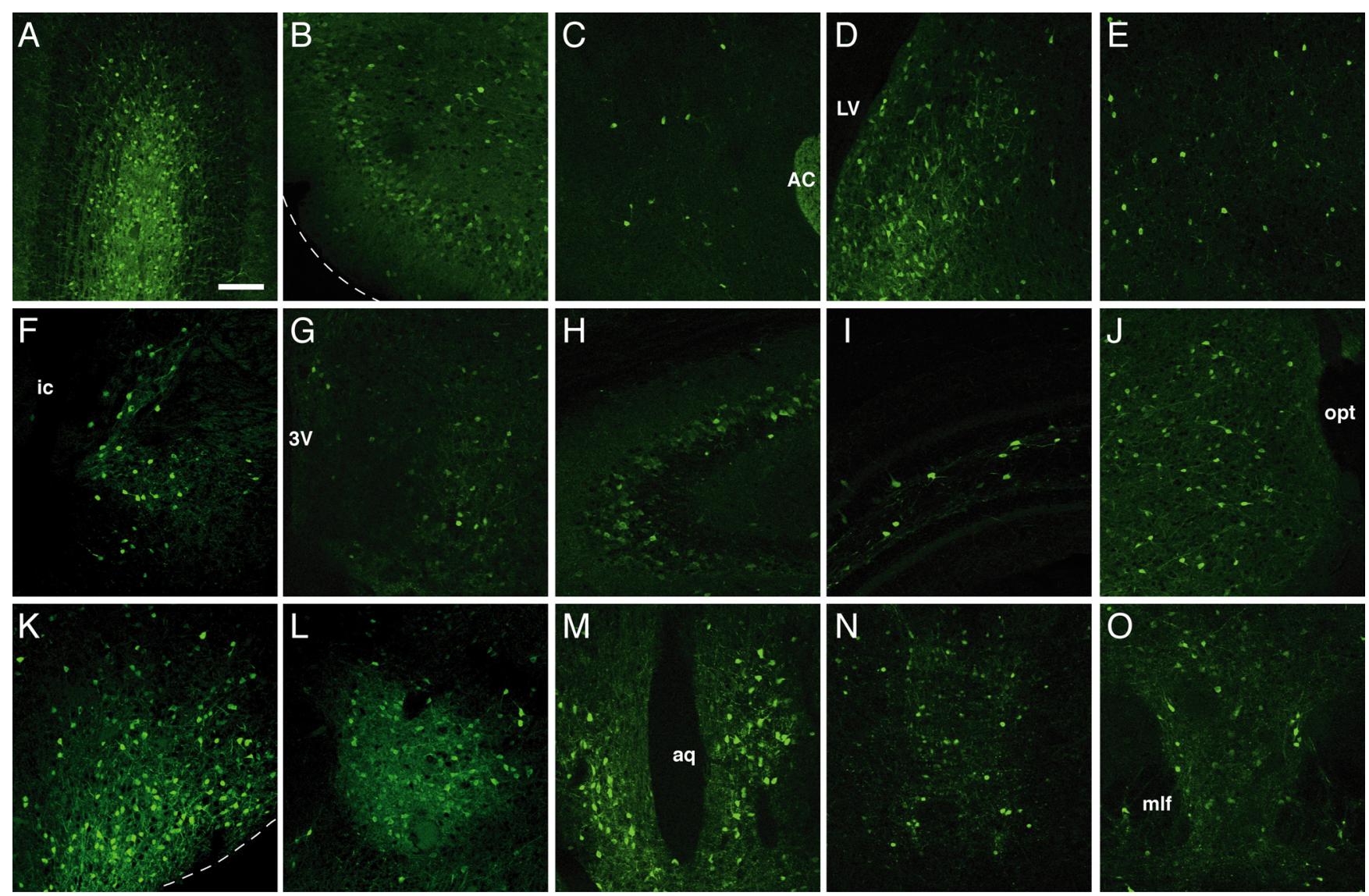

Figure 3. The distribution of Venus immunoreactivity in the brain of male $0 x t r$ Venus $\triangle$ Neo/+ mice. Immunoreactive cells for Venus were found in $\operatorname{GrO}(\boldsymbol{A}), \operatorname{Pir}(\boldsymbol{B}), \operatorname{AccC}(\boldsymbol{C}), \operatorname{LS}(\boldsymbol{D}), \operatorname{PFC}(\boldsymbol{E}), \operatorname{BST}(\boldsymbol{F})$, $\operatorname{MPA}(\boldsymbol{G}), \mathrm{CA2}$, CA3 $(\boldsymbol{H}), \operatorname{PoDG}(\boldsymbol{I}), \operatorname{MeA}(\boldsymbol{J}), \mathrm{CoA}(\boldsymbol{K}), \operatorname{CeA}(\boldsymbol{L}), \operatorname{PAG}(\boldsymbol{M}), \operatorname{MnR}(\boldsymbol{N})$, and DR ( $\boldsymbol{O})$. Scale bar, $100 \mu \mathrm{m}$. AC, Anterior commissure; LV, lateral ventricle; ic, internal capsule; $3 V$, third ventricle; opt, optic chiasm; aq, aqueduct; mlf, medial longitudinal fasciculus.

were collected from the outflow using a micro fraction-collector (EFC82; Eicom) at $4^{\circ} \mathrm{C}$, starting $90 \mathrm{~min}$ after insertion of the probe (Onaka et al., 1995). OXT or the vehicle was applied through the microdialysis probe. To minimize oxidation of samples, $8 \mu \mathrm{l}$ of $0.23 \mathrm{M}$ acetic acid was added to each sampling tube. The position of the probe was confirmed by histological examination. Concentrations of serotonin were measured by HPLC with electrochemical detection. A $20 \mu \mathrm{l}$ aliquot was applied to a C18 reverse-phase column $(2.0 \times 200 \mathrm{~mm}$; Eicopack CAX; Eicom $)$ at $35^{\circ} \mathrm{C}$. An electrochemical detector (ECD-300; Eicom) was set at a potential of $450 \mathrm{mV}$ relative to an $\mathrm{Ag}^{+}-\mathrm{AgCl}$ reference electrode. The mobile phase was $0.1 \mathrm{M}$ ammonium acetate buffer, $\mathrm{pH} 6$, containing $30 \%$ methanol, $0.0071 \%$ sodium sulfate, and $0.00005 \%$ ethylenediaminetetraacetic acid. The flow rate was $0.25 \mathrm{ml} / \mathrm{min}$. The mean value of the basal contents of serotonin in the first three perfusate samples before OXT or vehicle application was set as $100 \%$ in each animal.

Measurements of heart rate and core body temperature. Heart rates were measured by electrocardiogram. Body temperature was measured with a rectal temperature probe (model BDT-100; BRC).

Intracerebroventricular injection. C57BL/6J (SLC) male mice were anesthetized with Avertin and positioned in a stereotaxic frame. A stainless-steel guide cannula was inserted into the brain with the tip in the right lateral cerebral ventricle, and secured to the skull with screws and dental cement. The cannula tip was located $0.4 \mathrm{~mm}$ caudal to the bregma, $1.0 \mathrm{~mm}$ lateral to the midline, and $2.3 \mathrm{~mm}$ below the skull. Over 1 week after the surgery, experiments were performed. The position was verified with cresyl violet injected through the cannula after experiments.

Open-field test. To assess anxiety-related behavior and spontaneous locomotor activity, mice were placed into a corner of an open-field apparatus $(60 \times 60 \times 40 \mathrm{~cm})(\mathrm{O}$ 'Hara \& Co.). The chamber was illuminated (10 lux), under conditions previously validated to assess anxietyrelated behavior. Distance traveled and time spent in the center area was recorded over a $10 \mathrm{~min}$ period. Mice were injected intraperitoneally with ritanserin $(5 \mathrm{mg} / \mathrm{kg}$; injection volumes were $10 \mathrm{ml} / \mathrm{kg}$ ) or vehicle $45 \mathrm{~min}$ before test and intracerebroventricularly with OXT $(10 \mu \mathrm{g} / 2 \mu \mathrm{l})$ or vehicle 15 min before test.

Drug. Oxytocin (Peptide Institute) was dissolved in artificial CSF at a concentration of $5 \mathrm{mg} / \mathrm{ml}$. Ritanserin (RBI), a $5-\mathrm{HT}_{2 \mathrm{~A} / 2 \mathrm{C}}$ receptor selective antagonist was dissolved in DMSO at a concentration of $5 \mathrm{mg} / \mathrm{ml}$ and diluted with distilled water at a concentration of $500 \mu \mathrm{g} / \mathrm{ml}$. Acetic acid was added to the solution $(2 \mu \mathrm{l} / 10 \mathrm{ml})$.

Statistics. Data are expressed as mean \pm SEM. Data were analyzed using ANOVA or repeated-measures ANOVA, where appropriate, followed by Dunnett's $t$ test or $t$ test. Behavior data were analyzed using Mann-Whitney $U$ test. A value of $p<0.05$ was considered to be statistically significant.

\section{Results}

OXTR immunohistochemistry in Oxtr ${ }^{-/-}$and $\mathrm{Oxtr}^{+/+}$mice We first attempted to identify cells expressing OXTR in the mouse brain with immunohistochemistry by using several antibodies. Using identical procedures as were previously used to label OXTR immunoreactivity in the rat hypothalamus (Adan et al., 1994), as well as five commercially available antibodies (H-60, N-19, C-20; Santa Cruz Biotechnology; LS-A246, LS-A244; MBL) (data not shown), we detected moderate staining in the hypothalamus (Fig. 1), consistent with reported staining using different antibody in the female rat (Meddle et al., 2007). However, similar staining was also detected in the same region of $\mathrm{Oxtr}^{-1-}$ mice, suggesting that immunohistochemical staining using these anti- 
bodies is not a reliable technique for identifying OXTR-containing neurons in mice.

\section{Generation of OXTR-Venus \\ knock-in mice}

OXTR-Venus knock-in mice were generated by replacing part of the gene encoding OXTR with the cDNA for Venus (Fig. $2 A$ ). We used the Cre/loxP system to produce OXTR-Venus knock-in mice with the PGK-Neo deleted $\left(O x t^{\text {Venus } \Delta \mathrm{Neo} /+}\right)$. Venus transcripts, fluorescence, and protein were detected in Oxtr $\mathrm{Venus} \Delta \mathrm{Neo} /+$ mice (Fig. 2C,D). The disruption of the Oxtr gene locus (Fig. 2B), the absence of Oxtr transcripts (Fig. 2C), and the absence of OXTR binding (Fig. 2F,G) in $O x t r$ Venus $\Delta$ Neo/Venus $\Delta$ Neo mice confirmed that the recombined allele was null. In addition, the pattern of OXTR-binding in the brain was mostly consistent with that of Venus immunoreactivity (Fig. 2E,F).

\section{Distribution of Venus}

immunoreactivity in the male brain Venus-positive cells were observed in various regions throughout the Oxtr Venus $\Delta$ Neo/+ male brain (Table 1). The highest density of Venus-expressing cell bodies were observed in the granular cell layer of the olfactory bulb ( $\mathrm{GrO}$ ), LS, organum vasculosum of the lamina terminalis (OVLT), nucleus of the horizontal limb of the diagonal band, magnocellular preoptic nucleus, lateroanterior hypothalamic nucleus (LA), cortical amygdaloid nucleus (CoA), suprachiasmatic nucleus, ventromedial hypothalamic nucleus (VMH), arcuate hypothalamic nucleus (Arc), and prepositus nucleus (Table 1, Figs. 3, 4).

Moderate to strong expression of Venus was observed in prefrontal cortex (PFC), piriform cortex (Pir), accumbens nucleus core (AccC), medial preoptic area (MPA), bed nucleus of the stria terminalis (BST), medial amygdaloid nucleus (MeA), central amygdaloid nucleus (CeA), CA2 and CA3 regions of the hippocampus, polymorphic layer of the dentate gyrus (PoDG), periaqueductal gray (PAG), DR, and MnR (Fig. 3). OXTR binding was observed in these areas (Fig. $2 F, G$ ) (data not shown), consistent with the previously reported data (Elands et al., 1988; Insel et al., 1993; Gimpl and Fahrenholz, 2001). We examined colocalization of Venus with GLAST, a marker of glial cells. Venus was observed in glial cells in the subfornical organ (SFO), OVLT, and molecular layer of the cerebellar cortex (CCmol) (Fig. 5).

We then examined colocalization of Venus with GABA immunoreactivity in a subset of nuclei most likely to be involved in the regulation of social and emotional behavior $(\mathrm{GrO}, \mathrm{Gl}, \mathrm{PFC}$, Pir, AccC, LS, MPA, BST, CoA, MeA, CeA, CA2 and CA3, PoDG, PAG, DR, and MnR). Venus was detected in GABAergic neurons in the LS, BST, and CoA, but very few in other areas (Fig. 6).

\section{Colocalization of Venus with monoamines}

Monoamines such as dopamine, noradrenaline, and serotonin play important roles in the regulation of social and emotional behavior (Insel and Young, 2001; Miczek et al., 2002; Nelson and Trainor, 2007). TH is the catecholamine synthetic enzyme and a maker molecule of dopaminergic, adrenergic, and noradrenergic cells. OXT has been reported to facilitate release of noradrenaline and dopamine within the brain (Lévy et al., 1995; Onaka et al., 2003; Melis et al., 2007). We examined whether Venus-positive neurons express TH immunoreactivity in the glomerular layer of the olfactory bulb (Gl) (the A16 dopaminergic cell region) (Fig. $7 A$ ), Arc (the A12 dopaminergic cell region) (Fig. $7 B$ ), ventral tegmental area (VTA) (the A10 dopaminergic cell region) (Fig. $7 C$ ), posterior and dorsal hypothalamic areas (the A11 dopaminergic cell region) (data not shown), PAG (the A11 and A10 dopaminergic cell region) (Fig. 7D), substantia nigra (the A9 dopaminergic cell region) (data not shown), locus ceruleus (LC) (the A6 noradrenaline cell region) (Fig. 7E), NTS (the A2/C2 noradrenaline/adrenergic cell regions) (Fig. $7 F$ ), and ventrolateral medulla (the $\mathrm{A} 1 / \mathrm{C} 1$ noradrenaline/adrenergic cell regions) (data not shown). Colocalization with $\mathrm{TH}$ was observed only in the PAG (Fig. 7D).

We also determined whether Venus-positive cells express $\mathrm{TrH}$, a marker of serotonergic neurons (Fig. 8). Throughout the entire DR and MnR Venus-positive cells were found and a considerable number of Venus-positive cells contained $\mathrm{TrH}$ immunoreactivity. A three-dimensional image constructed from serial tomographical images confirms that $\mathrm{TrH}$-positive cells expressed Venus immunoreactivity (Fig. $8 B, D$ ).

In the DR, $25.6 \pm 8.0 \%$ of TrH-positive cells expressed Venus immunoreactivity and $32.0 \pm 3.7 \%$ of Venus-positive cells expressed $\mathrm{TrH}$ immunoreactivity. In the MnR, $49.0 \pm 5.3 \%$ of TrH-positive cells expressed Venus immunoreactivity and $43.9 \pm 5.8 \%$ of Venus-positive cells expressed $\mathrm{TrH}$ immunoreactivity. We also confirmed that OXTR binding was observed in the DR and MnR (Fig. 2G). Colocalization of Venus with $\mathrm{TrH}$ is also observed from embryonic day 17.0 in the DR and MnR (Fig. 
A

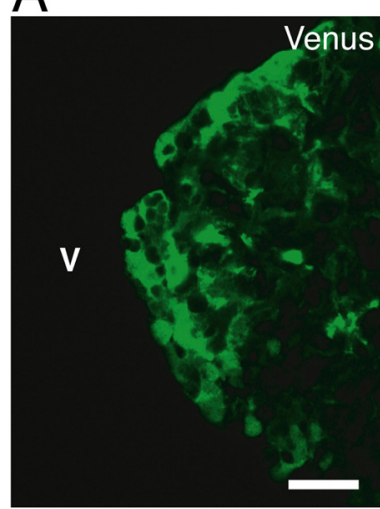

B

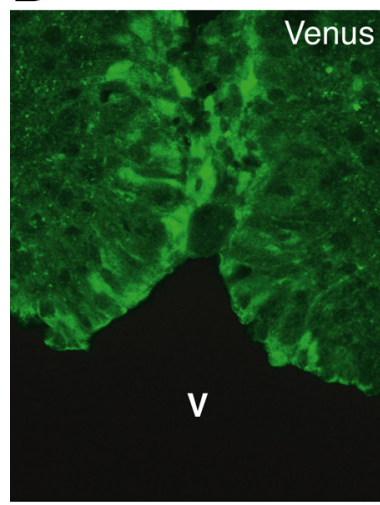

C
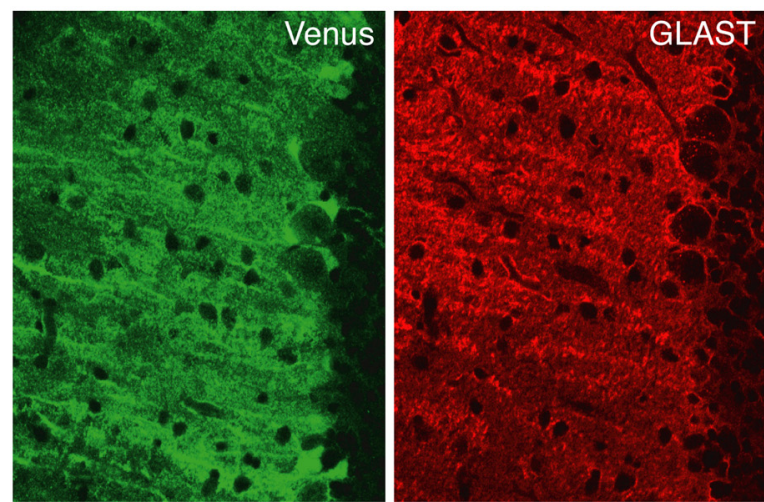
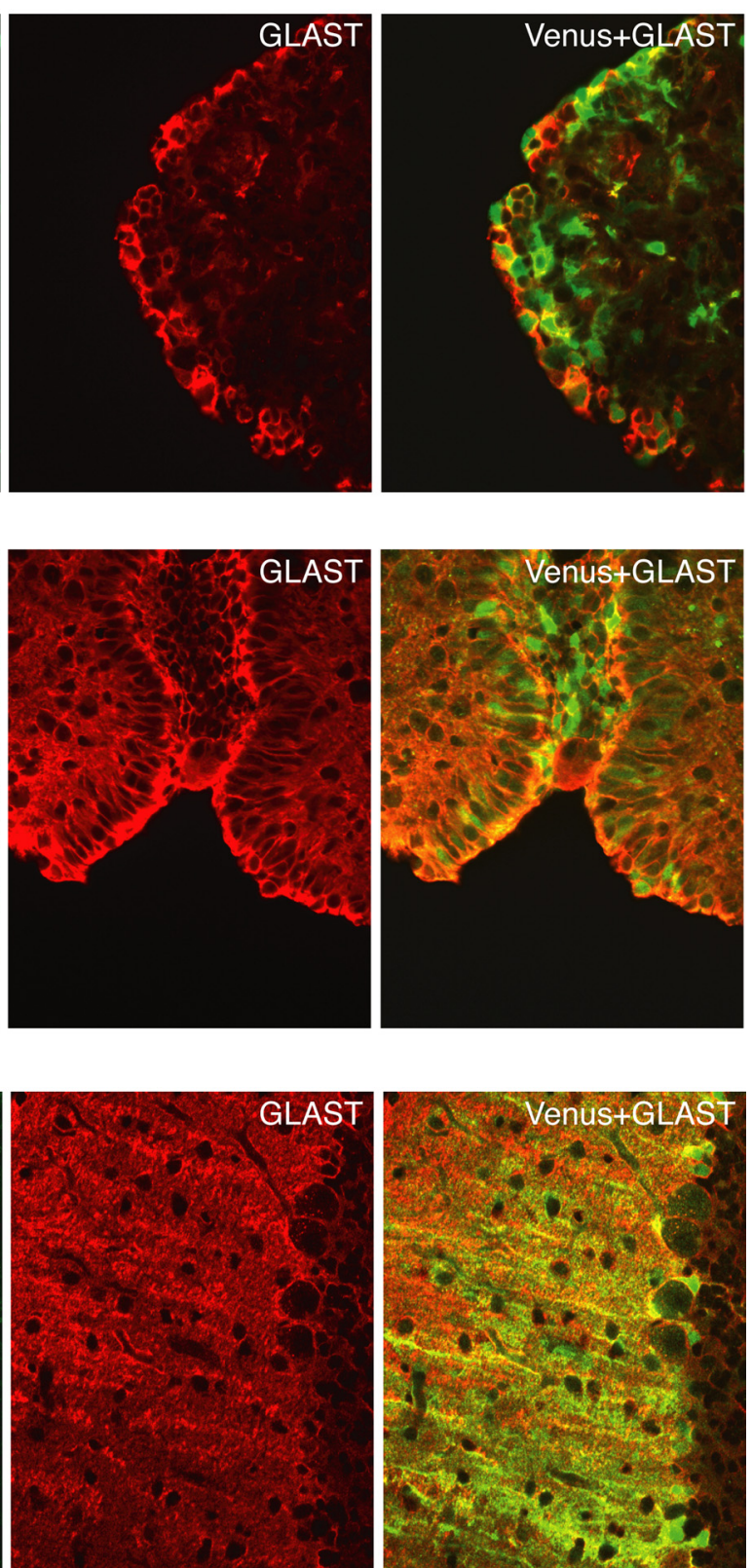

Figure 5. Double immunocytochemical detection of Venus and GLAST, a marker of glial cells. GLAST-immunoreactive cells expressed Venus in the SFO (A), OVLT (B), and CCmol (C). Scale bar, $30 \mu \mathrm{m}$. V, Ventricle.

9). All these data indicate that a considerable number of serotonergic neurons expressed OXTR and suggest that activation of OXTR regulates activity of serotonergic neurons from embryonic stage to adult.

\section{OXT-induced release of serotonin in MnR}

We examined the effects of local application of OXT on serotonin release in wild-type mice. OXT was applied locally within the MnR via a microdialysis probe. Serotonin release within the MnR was significantly facilitated during application of OXT but not the vehicle (Fig. 10A). After application of OXT, heart rates and body temperature were significantly increased compared with those before OXT perfusion $(45 \mathrm{~min})$ or those of the vehicleperfused control mice (Fig. 10B).
$5-\mathrm{HT}_{2 \mathrm{~A} / 2 \mathrm{C}}$ receptor antagonist prevents the anxiolytic effects of oxytocin

We then investigated anxiety-related behavior to assess the physiological functions of the OXT-serotonin pathway. Mice were injected with OXT (10 $\mu$ g, i.c.v. $)$ and ritanserin $\left(5 \mathrm{mg} / \mathrm{kg}\right.$, i.p.), a $5-\mathrm{HT}_{2 \mathrm{~A} / 2 \mathrm{C}}$ receptor antagonist which crosses blood-brain barrier, and tested with an open-field test. Intracerebroventricular administration of OXT significantly increased time spent in the center field, suggesting that OXT has an anxiolytic action. The anxiolytic effect of OXT was blocked by coadministration of ritanserin, indicating that $5-\mathrm{HT}_{2 \mathrm{~A} / 2 \mathrm{C}}$ receptor activation is necessary for anxiolytic effects of oxytocin (Fig. 11).

\section{Discussion}

Receptor autoradiography and in situ hybridization have demonstrated that OXTR-expressing regions are distributed in specific regions of the brain (Elands et al., 1988; Insel et al., 1993; Yoshimura et al., 1993; Vaccari et al., 1998). However, these techniques have not been useful for characterizing OXTR-expressing cells at the cellular level. Immunohistochemistry has previously been used to localize OXTR immunoreactivity in the rat brain (Adan et al., 1995; Meddle et al., 2007). We attempted to use this technique to identify cells expressing OXTR in the mouse brain using several antibodies to OXTR. However, we found moderate staining in the hypothalamus even in the brain of $\mathrm{Oxtr}^{-1-}$ mice, indicating that these antibodies used are not sensitive and selective enough for identifying cellular localization in mice. We therefore generated an OXTR reporter mouse strain by replacing part of the Oxtr gene with the cDNA for Venus. These knock-in mice enabled us to identify and neurochemically characterize the OXTR-expressing cells at a cellular level. The present study indicates that some OXTR-expressing cells contain GABA and monoamines. However, the most intriguing, and impressive colocalization results from this study were that of Venus in $\mathrm{TrH}$-positive neurons in the raphe nuclei.

In the present study, the expression of Venus was observed in virtually all regions previously reported to express Oxtr mRNA by in situ hybridization (Yoshimura et al., 1993; Vaccari et al., 1998). Previous studies shown that Oxtr mRNA localization are mostly consistent with OXTR binding sites (Yoshimura et al., 1993). We also showed that distribution of Venus is consistent with that of OXTR binding (Fig. 2E,F) (data not shown). From all these results, we speculate that OXTR is mainly expressed on the somata and/or dendrites.

We also found the expression of Venus in areas in which OXTR expression had not been described. These areas include MnR, OVLT, CCmol, LA, lateral hypothalamic area, median em- 
inence (ME), and area postrema (AP) (Figs. 3N, 4, 5B,C). The OVLT, ME, AP, and SFO contain high density of blood vessels that lack the blood brain-barrier, and face to the cerebral ventricle. These regions can detect humoral signals in the circulating system (Johnson and Gross, 1993). In the SFO and OVLT, Venus-positive cells expressed GLAST. Glial cells in the SFO have been shown to sense $\mathrm{Na}^{+}$levels in the body fluid and modulate the neuronal activity (Shimizu et al., 2007). It is tempting to speculate that OXTR-expressing glial cells in these areas serve as sensors for OXT in the blood and CSF.

Adult Oxtr ${ }^{-1-}$ males showed elevated aggressive behavior (Takayanagi et al., 2005). The neural network for aggressive behavior includes the MPA, LS, AH, VMH, PAG, MeA, CoA, and BST (Kollack-Walker and Newman, 1995; Nelson and Trainor, 2007). Among them, the LS has been shown to be activated during fighting (Nelson and Trainor, 2007) and to suppress aggressive behaviors (Siegel and Edinger, 1983). The LS sends GABAergic projection to target neurons in the basal ganglia, hypothalamic areas, and lower brainstem (Sheehan et al., 2004). The LS receives OXT projections from the hypothalamus (Gimpl and Fahrenholz, 2001). In the present study, Venus was colocalized in GABA-positive cells in the LS. It is thus interesting to speculate that OXT inhibits aggressive behavior via activation of GABAergic neurons in the LS. However, Venus-positive cells were found to exist in all the above areas, and thus multiple brain regions may be involved in the regulation of aggressive behavior by OXT.

The monoamines dopamine, noradrenaline, and serotonin play important roles in the regulation of social and emotional behavior (Insel and Young, 2001; Miczek et al., 2002; Nelson and Trainor, 2007). In our study, Venus-positive cells expressed $\mathrm{TH}$ immunoreactivity in the PAG, which plays a pivotal role in emotional behaviors, such as ultrasonic vocalization (Graeff et al., 1993; Hofer, 1996). Both dopaminergic and oxytocinergic transmissions influence ultrasonic vocalization (Missale et al., 1998; Takayanagi et al., 2005). It may be possible that these OXTR-expressing dopaminergic cells in the PAG are involved in ultrasonic vocalization. Venus was not detected in dopaminergic neurons in the VTA, which constitutes the mesolimbic dopamine pathway.

$\mathrm{Oxtr}^{-1-}$ mice, like OXT-deficient mice, display social amnesia (Takayanagi et al., 2005). In OXT-deficient mice, injections of OXT into the MeA effectively restored social recognition (Ferguson et al., 2001). In addition, blockade of OXTR signaling in the MeA by local application of an OXTR antagonist (Ferguson et al., 2001) or antisense oligodeoxynucleotides targeted to Oxtr mRNA (Choleris et al., 2007) impairs social recognition. These
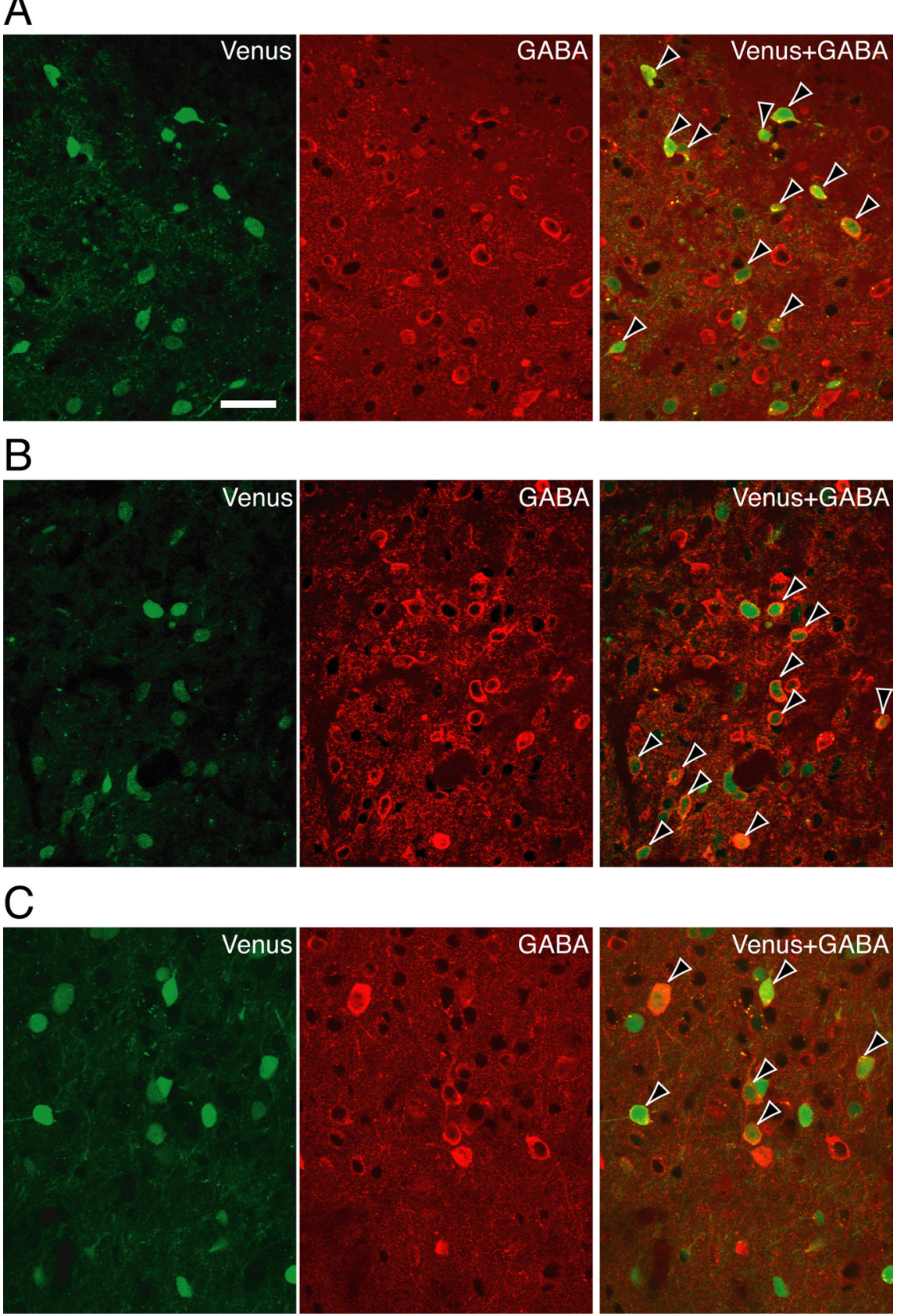

Figure 6. Colocalization of Venus with GABA. Venus and GABA were colocalized in the LS (A), BST $(\boldsymbol{B})$, and CoA (C). The arrowheads indicate double-positive cells for Venus (green) and GABA (red). Scale bar, $30 \mu \mathrm{m}$.

data indicate that OXTR activation in the MeA is essential for social recognition. However, detailed mechanisms by which OXTR in the MeA facilitates social behavior remain to be clarified. There were relatively few Venus-expressing neurons in the MeA, suggesting that the high density of OXTR binding in this region may originate mainly from presynaptic terminals. The MeA receives projections from several areas including the DR, PAG, and NTS (Aggleton, 2001), which contain high or medium density of Venus expression cells.

The OXTR-Venus knock-in mouse provides a valuable tool for discovering novel functions of the OXTR within neural circuits regulating behavior. Venus fluorescence is visible in living brain slices and it is thus possible to identify OXTR-expressing cells in these mice, suggesting that $O x t r^{\text {Venus } \Delta \mathrm{Neo} /+}$ mice are suit- 
A

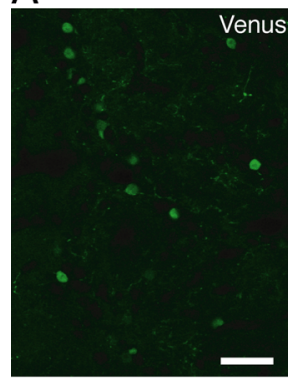

B

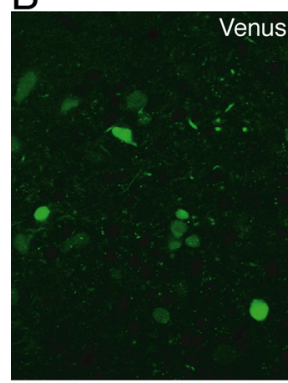

C

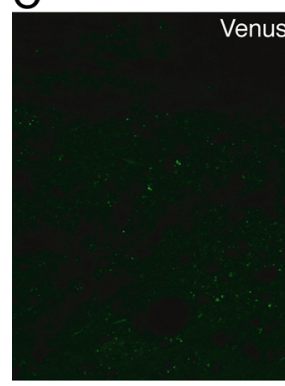

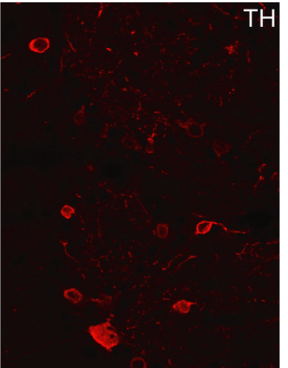
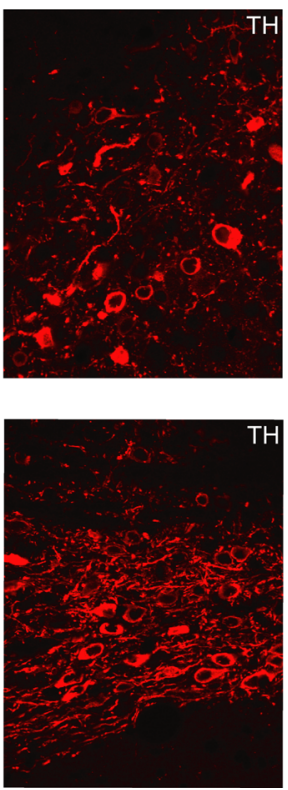
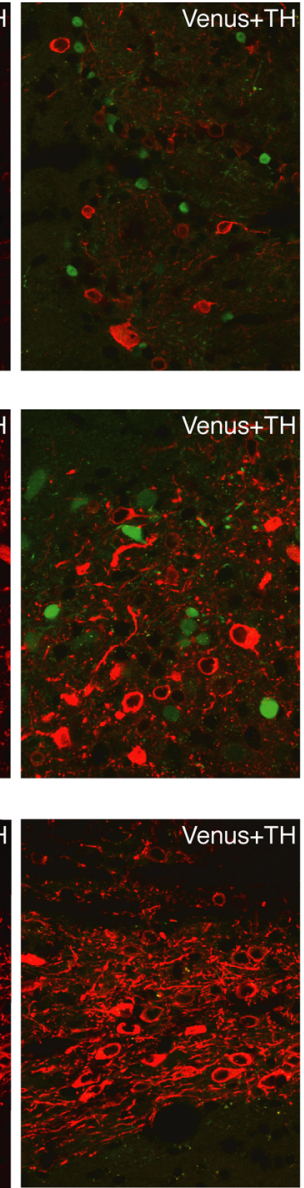

$\mathrm{D}$

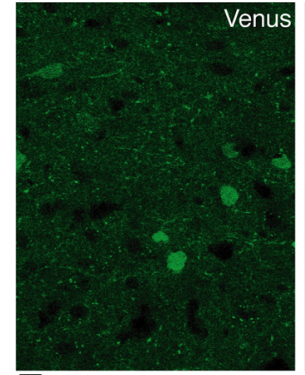

E

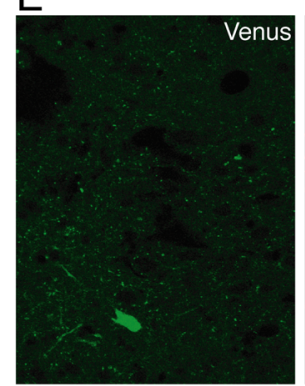

$\mathrm{F}$

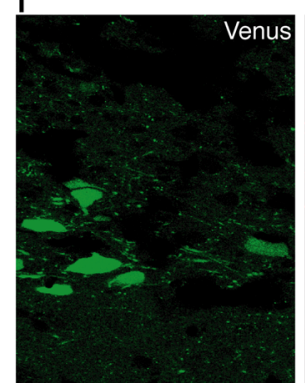

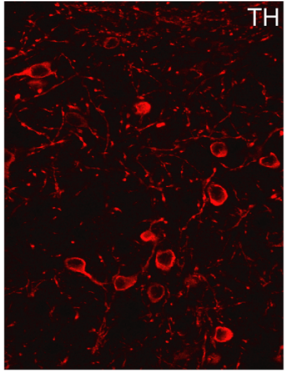
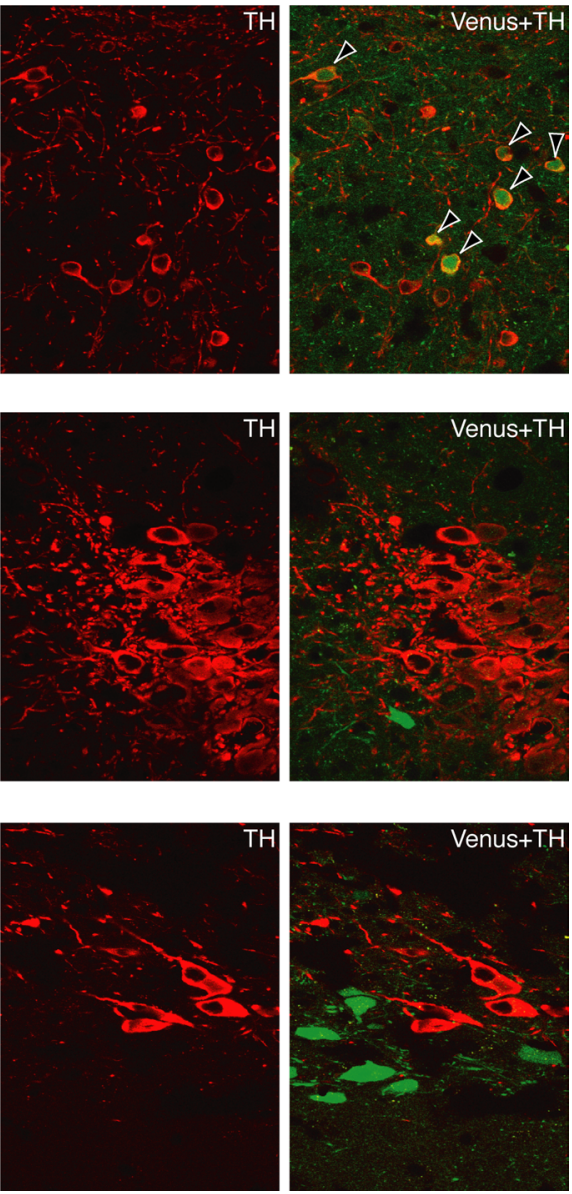

Figure 7. Colocalization of Venus with TH. Areas of brain shown in each figure are as follows: GI $(\boldsymbol{A}), \operatorname{Arc}(\boldsymbol{B}), \operatorname{VTA}(\boldsymbol{C}), \mathrm{PAG}(\boldsymbol{D}), \mathrm{LC}(\boldsymbol{E})$, and NTS $(\boldsymbol{F})$. TH-immunoreactive cells in the PAG were observed to express Venus. The arrowheads indicate double-positive cells for Venus (green) and TH (red). Scale bar, $30 \mu \mathrm{m}$.

able for characterization of electrophysiological properties in living OXTR-expressing cells.

Centrally administered OXT at a dose of $10 \mu \mathrm{g}$ produces anxiolytic effects and these effects are blocked by an OXTR antagonist (Ring et al., 2006), suggesting that OXT acts on OXTR to induce the anxiolytic action. Consistent with the data, $10 \mu \mathrm{g}$ of OXT decreased anxiety-related behavior in the present study. It should be noted that the dose of OXT used in this study was relatively high. However, numerous studies have demonstrated that endogenous OXT has anxiolytic actions. Administration of OXTR antagonists increase anxiety-related behavior in pregnant, lactating (Neumann et al., 2000), or mating animals (Waldherr and Neumann, 2007), and OXT-deficient female mice display enhanced anxiety-related behavior (Mantella et al., 2003).

Previous studies have shown that functions of OXT neurons are modulated by serotoninergic neurons. Central administration of serotonin receptor agonists stimulates oxytocin release from the pituitary (Jørgensen et al., 2003; de Jong et al., 2007; Thompson et al., 2007). Oxytocin neurons in the hypothalamus receive projection fibers containing serotonin transporters (Emiliano et al., 2007). Application of oxytocin in conjunction with $5-\mathrm{HT}_{2}$ receptor agonists induces bursting activity in spinal cord neurons (Pearson et al., 2003). However, no studies have demonstrated an effect of oxytocin on the serotonergic system. In the present study, examination of $O x t r$ Venus $\Delta \mathrm{Neo} /+$ mice revealed novel functional relationships between the OXT and serotonin systems. The majority of serotoninergic neurons in the MnR ex- pressed Venus, and therefore presumably express OXTR. Local application of OXT facilitated serotonin release within the MnR. Furthermore, we found that activation of the OXT-serotonin system has anxiolytic effects that are blocked by $5-\mathrm{HT}_{2 \mathrm{~A} / 2 \mathrm{C}}$ receptor antagonists, consistent with previous reports showing anxiolytic actions of $5-\mathrm{HT}_{2 \mathrm{~A} / 2 \mathrm{C}}$ receptors (Sánchez, 1995). Together, these data suggest that the OXT-serotonin pathway plays an important role in modulating anxiety. The serotonin system has been implicated in the neuropathology of depression, and current antidepressant drugs block the serotonin transporter, resulting in increased extracellular serotonin (Kent, 2000). There is some evidence of altered oxytocin systems in depression (Marazziti and Catena Dell'osso, 2008). Thus, we would predict that enhancing central OXTR neurotransmission would not only decrease anxiety, but may also have antidepressant effects through stimulating serotonin neurotransmission.

There is also evidence that the serotonin system plays a critical role in regulating maternal nurturing behavior. Pet-1-deficient mice, in which 5-HT synthesis is greatly reduced, have been reported to have severely reduced pup survival. Pup mortality in these mice is apparently attributable to a reduction in maternal nurturing behavior rather than a disruption in lactation abilities because pups are found to have milk in their stomach (LerchHaner et al., 2008). In addition, Pet-1-deficient male mice show enhanced aggressive behavior in a resident-intruder test (Hendricks et al., 2003). Because Oxtr ${ }^{-1-}$ mice display a similar disruption in maternal responsiveness and increased aggression 


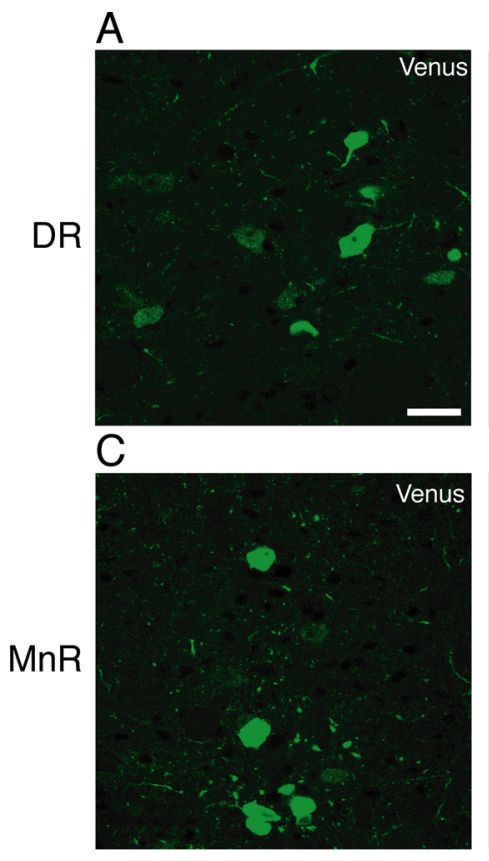

E

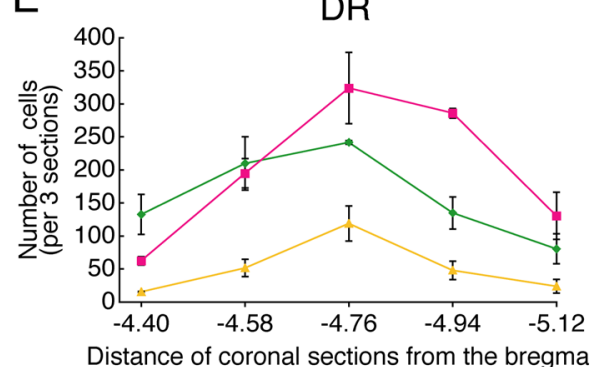

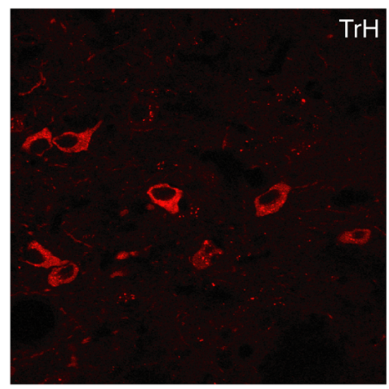
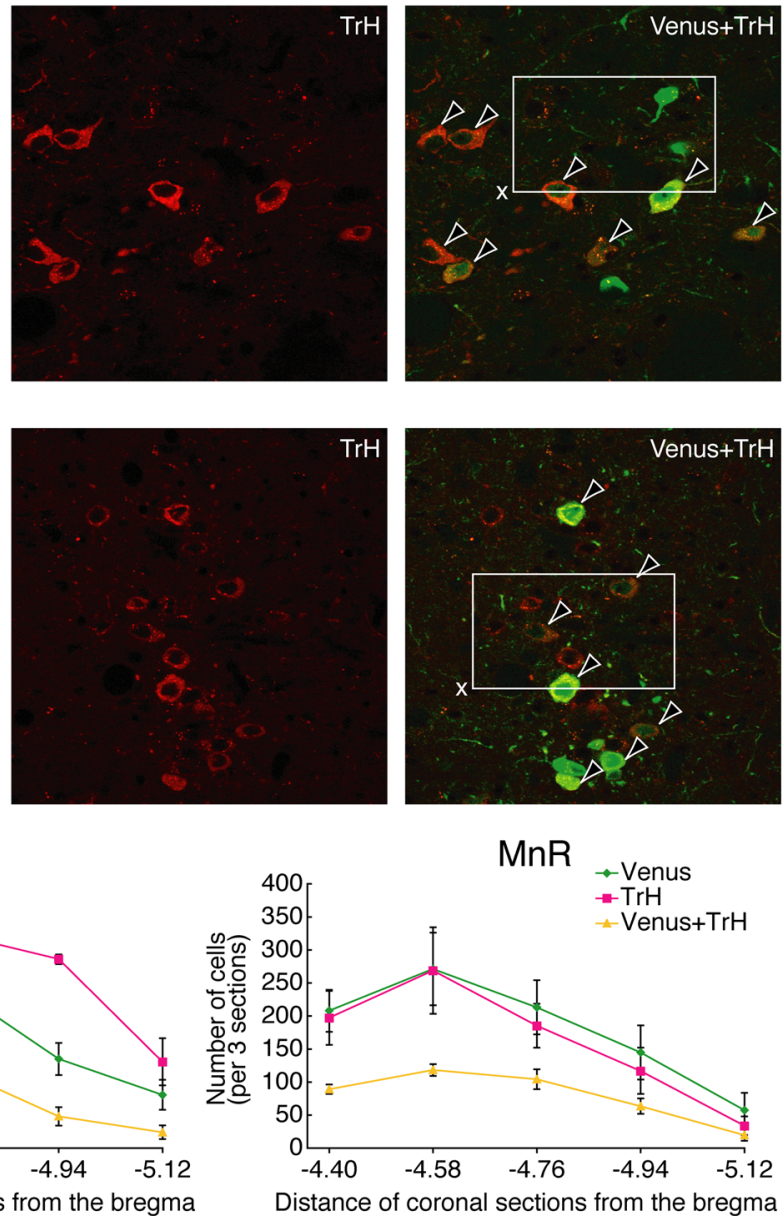

B

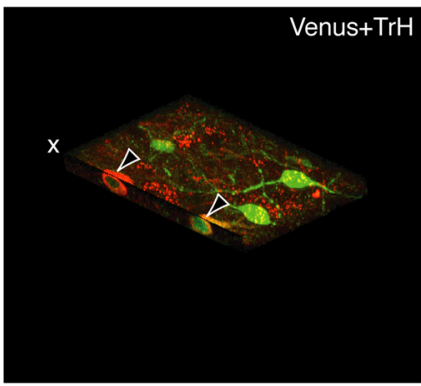

D

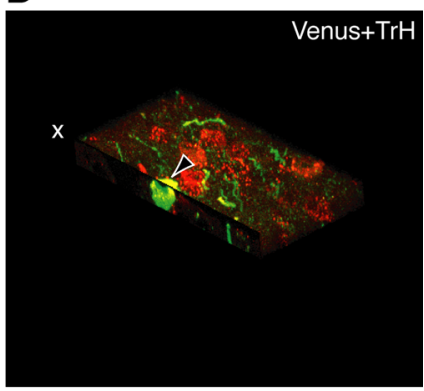

Figure 8. Double labeling of Venus with TrH. Colocalization of Venus with $\operatorname{TrH}$ in the $D R(\boldsymbol{A}, \boldsymbol{B})$ and $\operatorname{MnR}(\boldsymbol{C}, \boldsymbol{D})$. $\boldsymbol{B}$ and $\boldsymbol{D}$ show three-dimensional images constructed from serial tomographical images in open squares $(\boldsymbol{A}, \boldsymbol{C}) . \boldsymbol{E}$, Anteroposterior distribution of cells expressing immunoreactivity of Venus and/or TrH in the DR (left) and MnR (right) ( $n=3$ ). In the DR and MnR, about one-half of tryptophan hydroxylase-immunoreactive neurons were positive for Venus. Error bars indicate SEM. The arrowheads indicate double-positive cells for Venus (green) and TrH (red). Scale bar, 30 $\mu \mathrm{m}$.

(Takayanagi et al., 2005), it is tempting to speculate that oxytocinergic regulation of the serotonin system through OXTR in the raphe plays an essential role in maternal responsiveness and aggressive behavior. Both OXT and serotonin play an important role in neural development (Whitaker-Azmitia, 2001; Gross et al., 2002; Carter, 2003; Gingrich et al., 2003). Perinatal injections of OXT in prairie voles have an impact on behavior in adulthood (Kramer et al., 2003). In the present study, serotoninergic neurons expressed OXTR in embryonic brain. Our previous report suggests that embryonic exposure to OXT affects the development of aggressive behavior. It is thus tempting to speculate that OXT controls neural development via modulation of serotoninergic neurons.

Several human studies have implicated serotonin and OXT in the pathophysiology and genetics of autism (Green et al., 2001; Whitaker-Azmitia, 2001; Cho et al., 2007; Lerer et al., 2008). Animal studies have also demonstrated that mice deficient in serotonin receptors, the serotonin transporter, or OXTR exhibit pervasive social deficits (Brunner et al., 1999; Holmes et al., 2002; Miczek et al., 2002; Takayanagi et al., 2005). It is thus possible that OXT modulates not only anxiety-related behavior but also social behavior via serotoninergic transmission. These observations may provide new insights into psychiatric disorders associated with disruptions in social and emotional behavior, including autism, anxiety disorders, and depression.

\section{References}

Adan RA, Van Leeuwen FW, Sonnemans MA, Brouns M, Hoffman G, Verbalis JG, Burbach JP (1995) Rat oxytocin receptor in brain, pituitary, mammary gland, and uterus: partial sequence and immunocytochemical localization. Endocrinology 136:4022-4028.

Aggleton JP (2001) The amygdala: a functional analysis, Ed 2. London: Oxford UP.

Bergquist F, Ludwig M (2008) Dendritic transmitter release: a comparison of two model systems. J Neuroendocrinol 20:677-686.

Brunner D, Buhot MC, Hen R, Hofer M (1999) Anxiety, motor activation, and maternal-infant interactions in 5HT1B knockout mice. Behav Neurosci 113:587-601.

Carter CS (2003) Developmental consequences of oxytocin. Physiol Behav 79:383-397.

Cho IH, Yoo HJ, Park M, Lee YS, Kim SA (2007) Family-based association study of 5-HTTLPR and the 5-HT2A receptor gene polymorphisms with autism spectrum disorder in Korean trios. Brain Res 1139:34-41.

Choleris E, Little SR, Mong JA, Puram SV, Langer R, Pfaff DW (2007) Microparticle-based delivery of oxytocin receptor antisense DNA in the medial amygdala blocks social recognition in female mice. Proc Natl Acad Sci U S A 104:4670-4675.

de Jong TR, Veening JG, Olivier B, Waldinger MD (2007) Oxytocin involvement in SSRI-induced delayed ejaculation: a review of animal studies. J Sex Med 4:14-28.

Elands J, Beetsma A, Barberis C, de Kloet ER (1988) Topography of the oxytocin receptor system in rat brain: an autoradiographical study with a selective radioiodinated oxytocin antagonist. J Chem Neuroanat 1:293-302. 


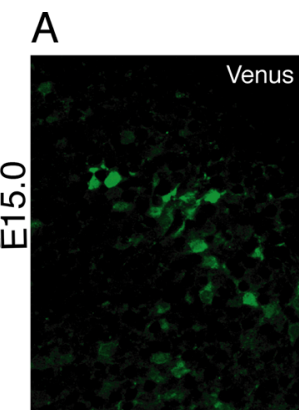

\section{B}

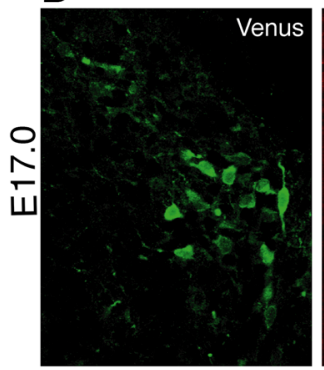

$\mathrm{C}$

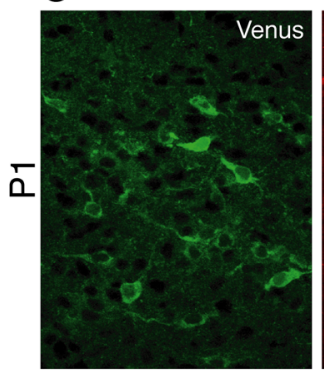

$\mathrm{D}$

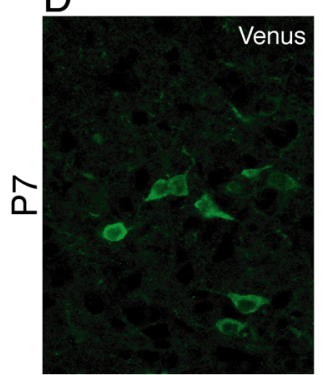

$\mathrm{E}$

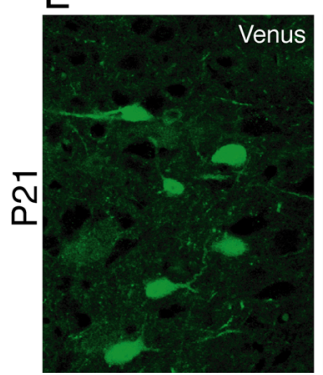

DR
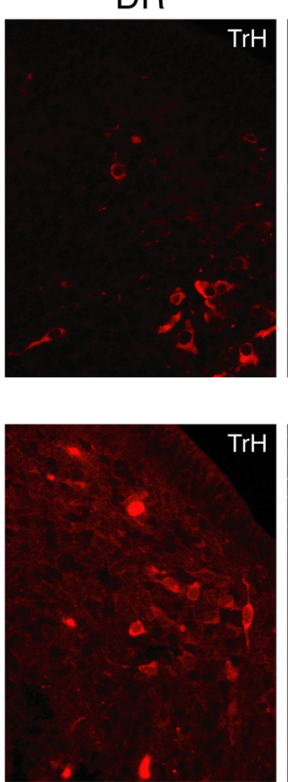

$\mathrm{THH}$
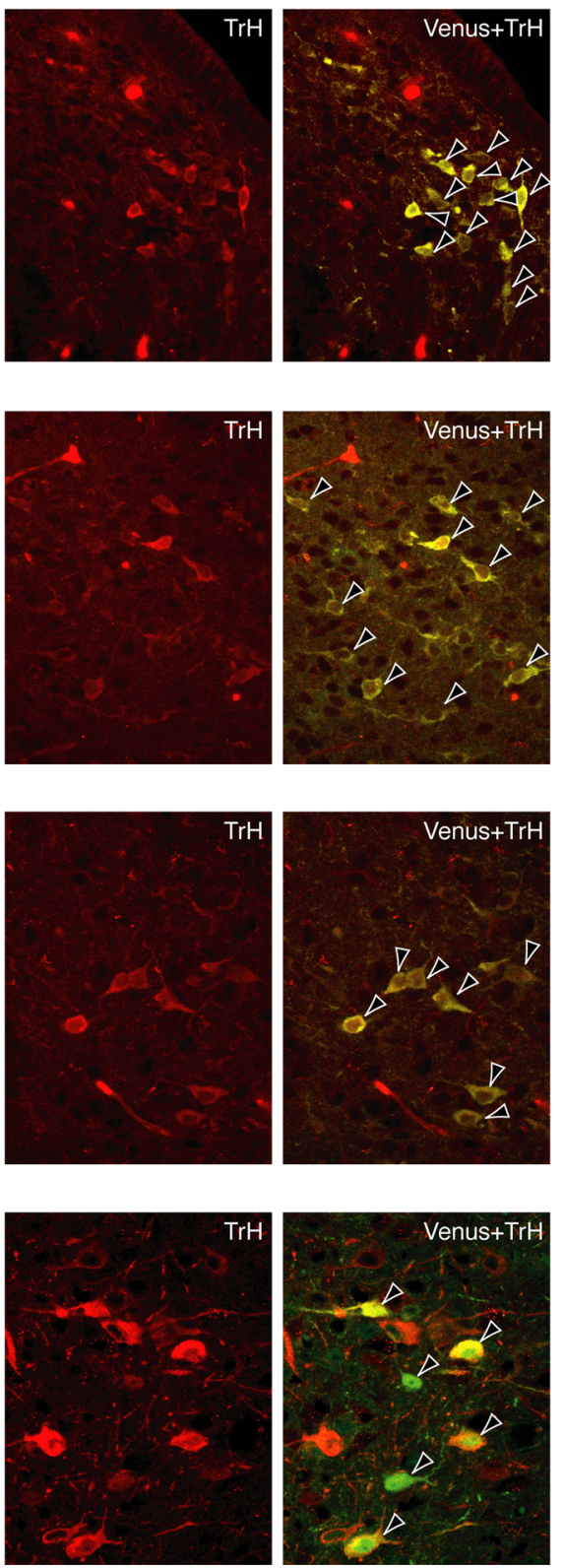

$\mathrm{F}$

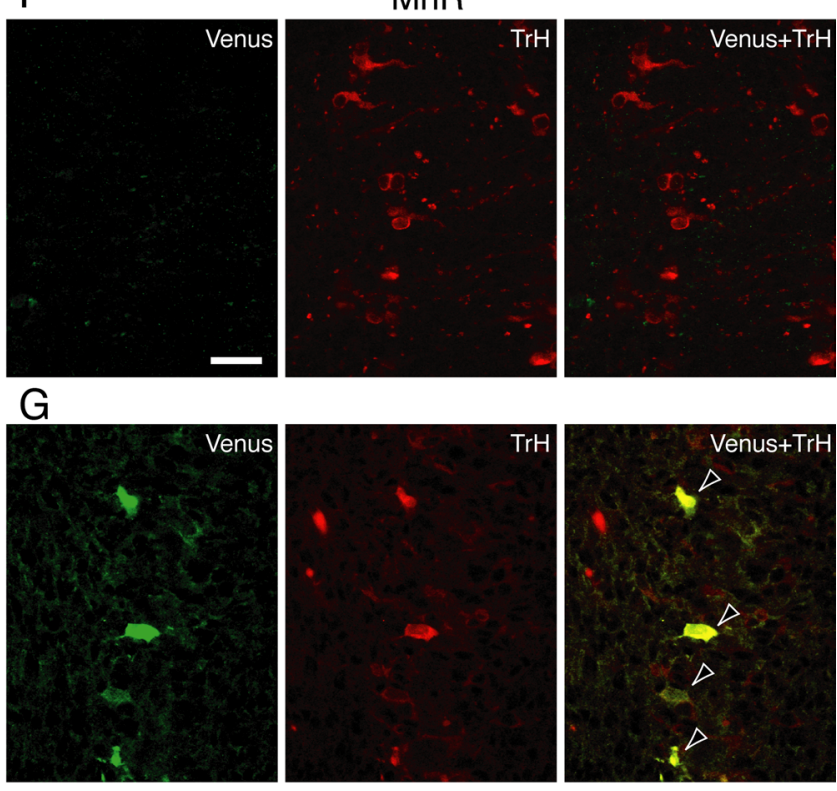

$\mathrm{H}$
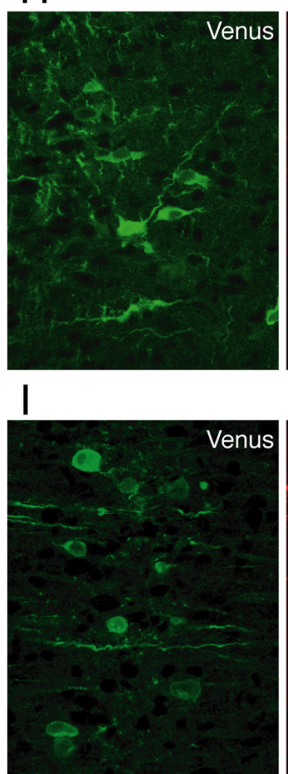

$\mathrm{J}$

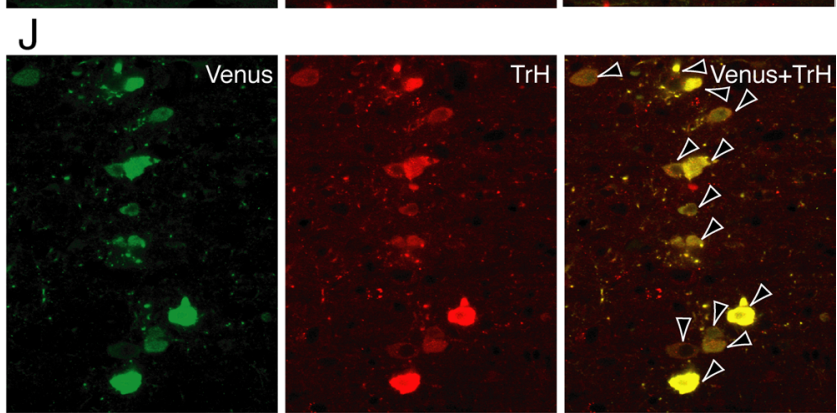

Figure 9. Developmental analysis of colocalization of Venus with $\operatorname{TrH}$ in the DR $(\boldsymbol{A}-\boldsymbol{E})$ and $\mathrm{MnR}(\boldsymbol{F}-\boldsymbol{J})$. The brains of Oxtr Venus $\Delta$ Neo/+ mice were analyzed at various developmental ages of embryonic day $15(\mathrm{E} 15)(\boldsymbol{A}, \boldsymbol{F}), \mathrm{E} 17(\boldsymbol{B}, \boldsymbol{G})$, and postnatal day $1(\mathrm{P} 1)(\boldsymbol{C}, \boldsymbol{H}), \mathrm{P} 7(\boldsymbol{D}, \boldsymbol{I})$, and P21 (E, J). The arrowheads indicate double-positive cells for Venus (green) and TrH (red). Scale bar, $30 \mu \mathrm{m}$.

Emiliano AB, Cruz T, Pannoni V, Fudge JL (2007) The interface of oxytocin-labeled cells and serotonin transporter-containing fibers in the primate hypothalamus: a substrate for SSRIs therapeutic effects? Neuropsychopharmacology 32:977-988.

Ferguson JN, Young LJ, Hearn EF, Matzuk MM, Insel TR, Winslow JT (2000) Social amnesia in mice lacking the oxytocin gene. Nat Genet 25:284-288.
Ferguson JN, Aldag JM, Insel TR, Young LJ (2001) Oxytocin in the medial amygdala is essential for social recognition in the mouse. J Neurosci 21:8278-8285.

Gimpl G, Fahrenholz F (2001) The oxytocin receptor system: structure, function, and regulation. Physiol Rev 81:629-683.

Gingrich JA, Ansorge MS, Merker R, Weisstaub N, Zhou M (2003) New lessons from knockout mice: the role of serotonin during development 
A
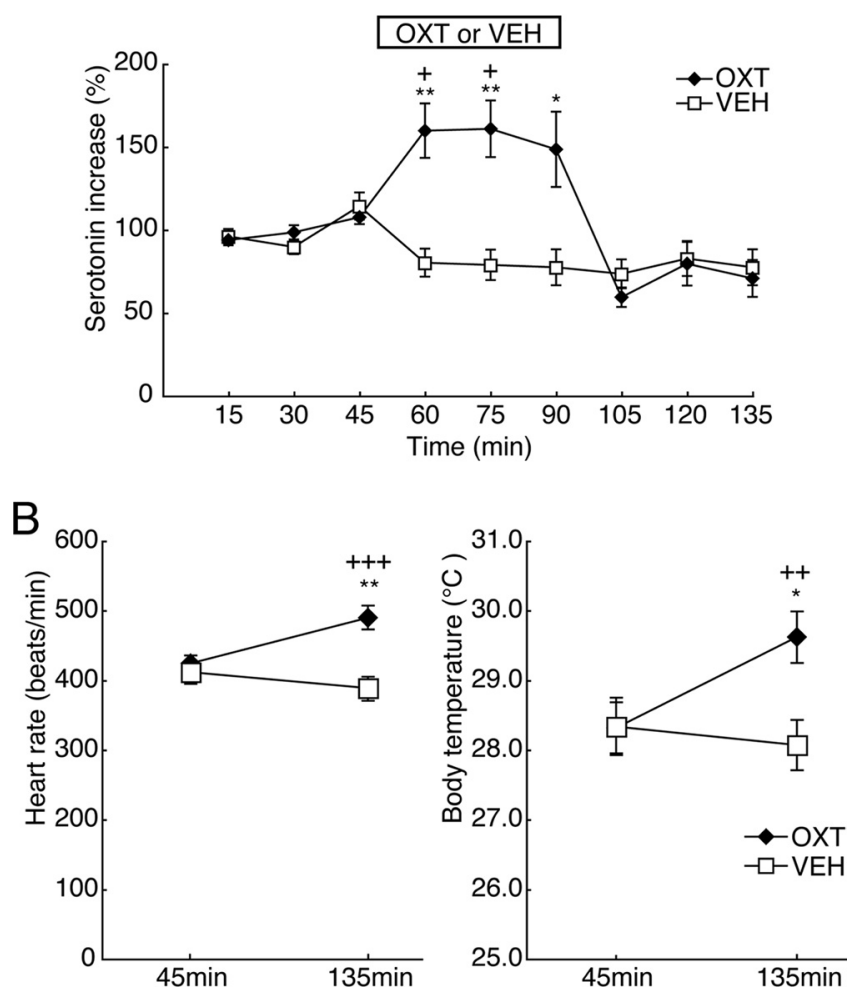

Figure 10. Facilitation of serotonin release in the MnR by local application of OXT. $\boldsymbol{A}$, The average content in the first three perfusates of the $\mathrm{MnR}$ was set as $100 \%$. One hundred percent for serotonin contents $=0.54 \pm 0.10$ (vehicle-perfused mice; $n=6$ ) or $0.36 \pm 0.05 \mathrm{pg} / 20 \mu \mathrm{l}$ (OXT-perfused mice; $n=7$ ). Serotonin release within the MnR was significantly facilitated during application of OXT but not the vehicle. ${ }^{*} p<0.05,{ }^{* *} p<0.01$ compared with vehicleperfused control group. ${ }^{+} p<0.05$ compared with the first three perfusate samples. $\boldsymbol{B}$, Effects of local application of OXT in the MnR on heart rates and body temperature. Heart rates (left) and body temperature (right) were significantly increased compared with those before OXT perfusion (45 min) or those of the vehicle-perfused control mice. ${ }^{*} p<0.05,{ }^{* *} p<0.01$ compared with vehicle-perfused control group. ${ }^{++} p<0.01,{ }^{+++} p<0.001$ compared with before OXT perfusion (45 min). Error bars indicate SEM.

and its possible contribution to the origins of neuropsychiatric disorders. CNS Spectr 8:572-577.

Graeff FG, Silveira MC, Nogueira RL, Audi EA, Oliveira RM (1993) Role of the amygdala and periaqueductal gray in anxiety and panic. Behav Brain Res 58:123-131.

Green L, Fein D, Modahl C, Feinstein C, Waterhouse L, Morris M (2001) Oxytocin and autistic disorder: alterations in peptide forms. Biol Psychiatry 50:609-613.

Gross C, Zhuang X, Stark K, Ramboz S, Oosting R, Kirby L, Santarelli L, Beck S, Hen R (2002) Serotonin1A receptor acts during development to establish normal anxiety-like behaviour in the adult. Nature 416:396-400.

Hendricks TJ, Fyodorov DV, Wegman LJ, Lelutiu NB, Pehek EA, Yamamoto B, Silver J, Weeber EJ, Sweatt JD, Deneris ES (2003) Pet-1 ETS gene plays a critical role in 5-HT neuron development and is required for normal anxiety-like and aggressive behavior. Neuron 37:233-247.

Hofer MA (1996) Multiple regulators of ultrasonic vocalization in the infant rat. Psychoneuroendocrinology 21:203-217.

Holmes A, Murphy DL, Crawley JN (2002) Reduced aggression in mice lacking the serotonin transporter. Psychopharmacology (Berl) 161:160-167.

Insel TR, Young LJ (2001) The neurobiology of attachment. Nat Rev Neurosci 2:129-136.

Insel TR, Young L, Witt DM, Crews D (1993) Gonadal steroids have paradoxical effects on brain oxytocin receptors. J Neuroendocrinol 5:619-628.

Johnson AK, Gross PM (1993) Sensory circumventricular organs and brain homeostatic pathways. FASEB J 7:678-686.

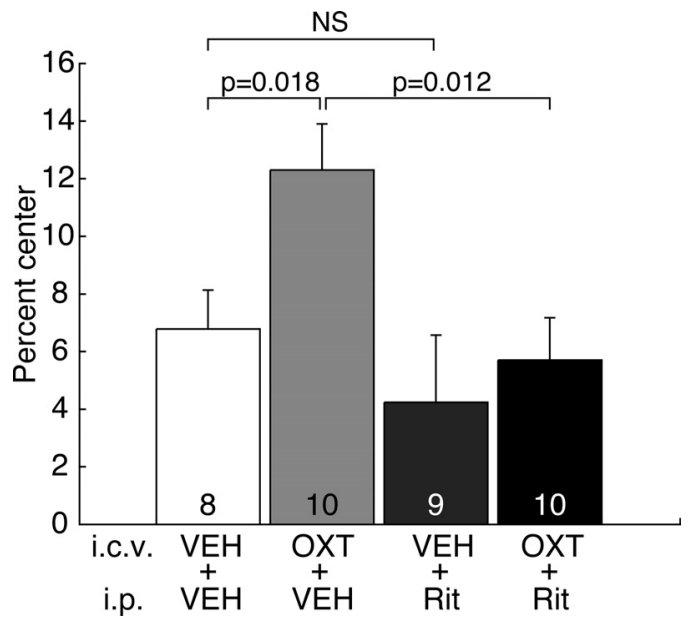

Figure 11. Anxiolytic effect of intracerebroventricular administration of OXT and reversal by $5-\mathrm{HT}_{2 \mathrm{~A} / 2 \mathrm{C}}$ receptor antagonist. Intracerebroventricular administration of OXT (10 $\mu$ g, i.c.v.) decreased anxiety-related behavior and the anxiolytic effect was blocked by coadministration of ritanserin $\left(5 \mathrm{mg} / \mathrm{kg}\right.$, i.p.), a $5-\mathrm{HT}_{2 \mathrm{~A} / 2 \mathrm{C}}$ receptor antagonist in the open-field test. The number of mice in each group is indicated in the bottom of each bar. Total distance traveled in each group was $2903 \pm 463,6305 \pm 622,2819 \pm 737$, and $4197 \pm 645 \mathrm{~cm}$ for mice injected with intracerebroventricular vehicle plus intraperitoneal vehicle, intracerebroventricular OXT plus intraperitoneal vehicle, intracerebroventricular vehicle plus intraperitoneal ritanserin, and intracerebroventricular OXT plus intraperitoneal ritanserin. Local application of OXT facilitated serotonin release within the raphe nucleus (Fig. $8 \mathrm{~A}$ ). Furthermore, anxiolytic effect of OXT was blocked by a $5-\mathrm{HT}_{2 \mathrm{~A} / 2 \mathrm{C}}$ receptor antagonist. Rit, Ritanserin; VEH, vehicle. Error bars indicate SEM.

Jørgensen H, Riis M, Knigge U, Kjaer A, Warberg J (2003) Serotonin receptors involved in vasopressin and oxytocin secretion. J Neuroendocrinol 15:242-249.

Kent JM (2000) SNaRIs, NaSSAs, and NaRIs: new agents for the treatment of depression. Lancet 355:911-918.

Kollack-Walker S, Newman SW (1995) Mating and agonistic behavior produce different patterns of Fos immunolabeling in the male Syrian hamster brain. Neuroscience 66:721-736.

Kramer KM, Cushing BS, Carter CS (2003) Developmental effects of oxytocin on stress response: single versus repeated exposure. Physiol Behav 79:775-782.

Kubota Y, Kimura T, Hashimoto K, Tokugawa Y, Nobunaga K, Azuma C, Saji F, Murata Y (1996) Structure and expression of the mouse oxytocin receptor gene. Mol Cell Endocrinol 124:25-32.

Lerch-Haner JK, Frierson D, Crawford LK, Beck SG, Deneris ES (2008) Serotonergic transcriptional programming determines maternal behavior and offspring survival. Nat Neurosci 11:1001-1003.

Lerer E, Levi S, Salomon S, Darvasi A, Yirmiya N, Ebstein RP (2008) Association between the oxytocin receptor (OXTR) gene and autism: relationship to Vineland Adaptive Behavior Scales and cognition. Mol Psychiatry 13:980-988.

Lévy F, Kendrick KM, Goode JA, Guevara-Guzman R, Keverne EB (1995) Oxytocin and vasopressin release in the olfactory bulb of parturient ewes: changes with maternal experience and effects on acetylcholine, gammaaminobutyric acid, glutamate and noradrenaline release. Brain Res 669:197-206.

Lim MM, Hammock EA, Young LJ (2004) A method for acetylcholinesterase staining of brain sections previously processed for receptor autoradiography. Biotech Histochem 79:11-16.

Ludwig M (1998) Dendritic release of vasopressin and oxytocin. J Neuroendocrinol 10:881-895.

Mantella RC, Vollmer RR, Li X, Amico JA (2003) Female oxytocin-deficient mice display enhanced anxiety-related behavior. Endocrinology 144:2291-2296.

Marazziti D, Catena Dell'osso M (2008) The role of oxytocin in neuropsychiatric disorders. Curr Med Chem 15:698-704.

Meddle SL, Bishop VR, Gkoumassi E, van Leeuwen FW, Douglas AJ (2007) Dynamic changes in oxytocin receptor expression and activation at parturition in the rat brain. Endocrinology 148:5095-5104.

Melis MR, Melis T, Cocco C, Succu S, Sanna F, Pillolla G, Boi A, Ferri GL, 
Argiolas A (2007) Oxytocin injected into the ventral tegmental area induces penile erection and increases extracellular dopamine in the nucleus accumbens and paraventricular nucleus of the hypothalamus of male rats. Eur J Neurosci 26:1026-1035.

Miczek KA, Fish EW, De Bold JF, De Almeida RM (2002) Social and neural determinants of aggressive behavior: pharmacotherapeutic targets at serotonin, dopamine and gamma-aminobutyric acid systems. Psychopharmacology (Berl) 163:434-458.

Missale C, Nash SR, Robinson SW, Jaber M, Caron MG (1998) Dopamine receptors: from structure to function. Physiol Rev 78:189-225.

Nagai T, Ibata K, Park ES, Kubota M, Mikoshiba K, Miyawaki A (2002) A variant of yellow fluorescent protein with fast and efficient maturation for cell-biological applications. Nat Biotechnol 20:87-90.

Nelson RJ, Trainor BC (2007) Neural mechanisms of aggression. Nat Rev Neurosci 8:536-546.

Neumann ID, Torner L, Wigger A (2000) Brain oxytocin: differential inhibition of neuroendocrine stress responses and anxiety-related behaviour in virgin, pregnant and lactating rats. Neuroscience 95:567-575.

Onaka T, Luckman SM, Guevara-Guzman R, Ueta Y, Kendrick K, Leng G (1995) Presynaptic actions of morphine: blockade of cholecystokinininduced noradrenaline release in the rat supraoptic nucleus. J Physiol 482:69-79.

Onaka T, Ikeda K, Yamashita T, Honda K (2003) Facilitative role of endogenous oxytocin in noradrenaline release in the rat supraoptic nucleus. Eur J Neurosci 18:3018-3026.

Pearson SA, Mouihate A, Pittman QJ, Whelan PJ (2003) Peptidergic activation of locomotor pattern generators in the neonatal spinal cord. J Neurosci 23:10154-10163.

Ring RH, Malberg JE, Potestio L, Ping J, Boikess S, Luo B, Schechter LE, Rizzo S, Rahman Z, Rosenzweig-Lipson S (2006) Anxiolytic-like activity of oxytocin in male mice: behavioral and autonomic evidence, therapeutic implications. Psychopharmacology (Berl) 185:218-225.

Sakai K, Miyazaki J (1997) A transgenic mouse line that retains Cre recombinase activity in mature oocytes irrespective of the cre transgene transmission. Biochem Biophys Res Commun 237:318-324.
Sánchez C (1995) Serotonergic mechanisms involved in the exploratory behaviour of mice in a fully automated two-compartment black and white text box. Pharmacol Toxicol 77:71-78.

Sheehan TP, Chambers RA, Russell DS (2004) Regulation of affect by the lateral septum: implications for neuropsychiatry. Brain Res Brain Res Rev 46:71-117.

Shimizu H, Watanabe E, Hiyama TY, Nagakura A, Fujikawa A, Okado H, Yanagawa Y, Obata K, Noda M (2007) Glial Nax channels control lactate signaling to neurons for brain $\left[\mathrm{Na}^{+}\right]$sensing. Neuron 54:59-72.

Siegel A, Edinger HM (1983) Role of the limbic system in hypothalamically elicited attack behavior. Neurosci Biobehav Rev 7:395-407.

Takayanagi Y, Yoshida M, Bielsky IF, Ross HE, Kawamata M, Onaka T, Yanagisawa T, Kimura T, Matzuk MM, Young LJ, Nishimori K (2005) Pervasive social deficits, but normal parturition, in oxytocin receptordeficient mice. Proc Natl Acad Sci U S A 102:16096-16101.

Thompson MR, Callaghan PD, Hunt GE, Cornish JL, McGregor IS (2007) A role for oxytocin and 5- $\mathrm{HT}_{1 \mathrm{~A}}$ receptors in the prosocial effects of 3,4 methylenedioxymethamphetamine ("ecstasy"). Neuroscience 146: 509-514.

Vaccari C, Lolait SJ, Ostrowski NL (1998) Comparative distribution of vasopressin V1b and oxytocin receptor messenger ribonucleic acids in brain. Endocrinology 139:5015-5033.

Waldherr M, Neumann ID (2007) Centrally released oxytocin mediates mating-induced anxiolysis in male rats. Proc Natl Acad Sci U S A 104:16681-16684.

Whitaker-Azmitia PM (2001) Serotonin and brain development: role in human developmental diseases. Brain Res Bull 56:479-485.

Yoshimura R, Kiyama H, Kimura T, Araki T, Maeno H, Tanizawa O, Tohyama M (1993) Localization of oxytocin receptor messenger ribonucleic acid in the rat brain. Endocrinology 133:1239-1246.

Zimmerman EA, Nilaver G, Hou-Yu A, Silverman AJ (1984) Vasopressinergic and oxytocinergic pathways in the central nervous system. Fed Proc 43:91-96. 